Rhode Island College

Digital Commons @ RIC

\title{
The Relationship between Tactical Knowledge and Tactical Performance for Varying Levels of Expertise
}

Robin Kirkwood Auld

Rhode Island College

Follow this and additional works at: https://digitalcommons.ric.edu/etd

Part of the Educational Psychology Commons, and the Sports Sciences Commons

\section{Recommended Citation}

Auld, Robin Kirkwood, "The Relationship between Tactical Knowledge and Tactical Performance for Varying Levels of Expertise" (2006). Master's Theses, Dissertations, Graduate Research and Major Papers Overview. 1.

https://digitalcommons.ric.edu/etd/1

This Dissertation is brought to you for free and open access by the Master's Theses, Dissertations, Graduate Research and Major Papers at Digital Commons @ RIC. It has been accepted for inclusion in Master's Theses, Dissertations, Graduate Research and Major Papers Overview by an authorized administrator of Digital Commons @ RIC. For more information, please contact digitalcommons@ric.edu. 
THE RELATIONSHIP BETWEEN TACTICAL KNOWLEDGE AND TACTICAL PERFORMANCE FOR VARYING LEVELS OF EXPERTISE

BY

ROBIN KIRKWOOD AULD

A DISSERTATION SUBMITTED IN PARTIAL FULFILLMENT OF THE REQUIREMENTS FOR THE DEGREE OF DOCTOR OF PHILOSOPHY

IN

EDUCATION

UNIVERSITY OF RHODE ISLAND

AND

RHODE ISLAND COLLEGE

2006 


\title{
DOCTOR OF PHILOSOPHY DISSERTATION
}

OF

ROBIN KIRKWOOD AULD

\begin{abstract}
APPROVED:
Dissertation Committee

Major Professor

ASSOCIATE DEAN OF THE GRADUATE SCHOOL-RIC

$\overline{\text { DEAN OF THE GRADUATE SCHOOL-URI }}$
\end{abstract}

UNIVERSITY OF RHODE ISLAND

AND

RHODE ISLAND COLLEGE

2006 


\begin{abstract}
This study examines the relationship between off-the-ball tactical knowledge and off-the-ball tactical performance of college-age female participants' $(n=34)$ with varying levels of expertise in territorial games. Tactical knowledge was measured using the Tactical Knowledge Instrument (TKI), which assessed participant responses when solving a "maintaining possession" tactical problem on a game board. The Game Performance Assessment Instrument (GPAI) measured participants' tactical performance while they played a directional keep-away game in the gymnasium.

Analysis of variance tests revealed a significant difference between the tactical knowledge scores between Expert and Novice participants $F(2,31)=6.09, p=.0059$. As the expertise level moved from Novice to Expert mean scores increased. Correlated t-tests were completed to investigate scoring differences among specific components of the GPAI. Tests revealed significant differences $(p<.001)$ with the decision-making; synchronized movement with teammates (DMB) and adjust; eluding a teammate prior to cutting to space $(\mathrm{AB})$ component scores when compared to all other GPAI component scores. The DMB and AB mean scores were significantly lower than other component scores for all expertise levels.

Off-the-ball knowledge and off-the-ball performance scores were not correlated among expertise groups. Expertise also did not prove to be an accurate indicator of participants' level of tactical knowledge (other than between Expert and Novice) or tactical performance. These results may have implications concerning the over emphasis of skill versus tactical-based teaching and coaching, and may help select the instructional methods best suited for territorial games.
\end{abstract}




\section{ACKNOWLEDGEMENT}

As I complete this Ph.D. journey I want my family, friends, and colleagues (especially those in the Health and Physical Education Department at Rhode Island College) to know how much I appreciate and value your continued support and encouragement. I would like to give special recognition to Mr. Paul Janaway and Dr. Bennett Lombardo for their preliminary suggestions toward modifying the study instruments and the endless hours of viewing, reviewing, and then scoring participant videotapes for both the validation and dissertation studies.

I am most grateful to my committee members who have committed much time and energy into guiding me through this process and ensuring I produce a meaningful end product.

Karen Castagno - you always found the answers to the endless logistical questions. I never felt alone as you were always quick to reassure me or relieve my anxieties. You handled the details so I could concentrate on the research. I trusted you completely to make sure the process was done correctly. Your attention to detail especially during the data collection and editing phases was extraordinary. You listened, suggested alternatives, but ultimately let this be my work.

Ben Lombardo - you were always willing to put down your work to listen to me think out loud about the teaching of games - I love talking sports with you!!! You were always positive, open to new views and helped me to develop my constructivist ideas through teaching games for understanding. I respect your views and suggestions and value you as a friend.

Lou Heifetz - thank you for your patience with my timetables and endless statistical questions for both my validation study and dissertation. Your in depth review of my drafts provided invaluable feedback. I feel fortunate to have had you on my team since the very beginning of the program; you gave me a solid foundation, which made me confident in the design and statistical analysis of my study.

David Byrd - your comments and suggestions on my initial literature review in Core II provided a starting point for my research. You helped me to pinpoint and redefine what I wanted to study and the questions you posed made me think about the big picture and where this research fit into school reform.

In addition, I want to recognize those who have shown unwavering loyalty and patience; especially through the last five years.

Andy - when all is said and done you are always there to keep everything real and in perspective. Throughout this process you gave me the time and space to work, however, I always knew and felt that you appreciated the importance of this accomplishment. I always knew you were in my corner and I love you for that.

Mom \& Dad - where it all started!!! Dad for introducing me to the world of sport; your unconditional support whether I was playing, coaching, recruiting, or we were just watching sports together - you planted the seed. Then Mom you nurtured my growth; you always let me know that I could do whatever I put my mind to and you modeled for me the qualities of a successful, strong woman. 


\section{TABLE OF CONTENTS}

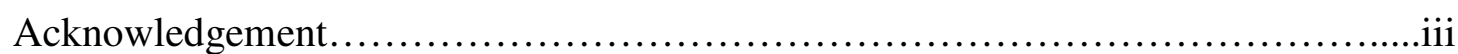

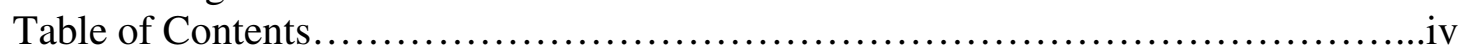

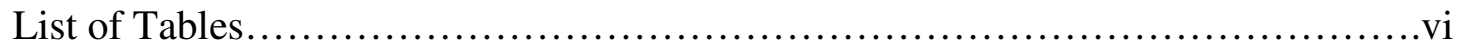

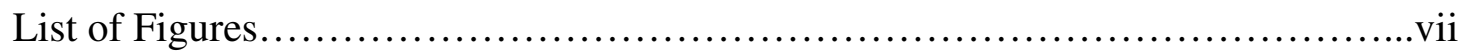

\section{INTRODUCTION}

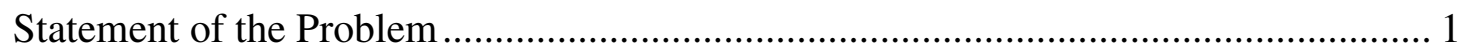

Justification for Significance of the Study ……………............................................ 3

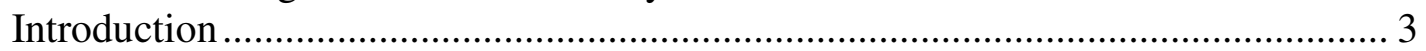

Relationship between Tactical Knowledge and Performance.................................. 5

Expertise and Rate of Improvement ................................................................... 8

Assessment of Tactical Knowledge and Performance .............................................. 11

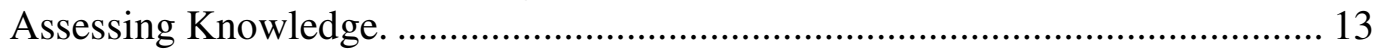

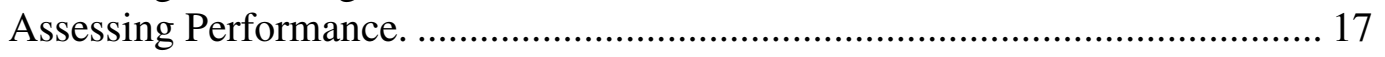

\section{METHOD}

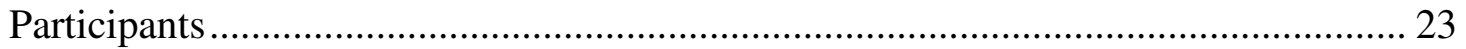

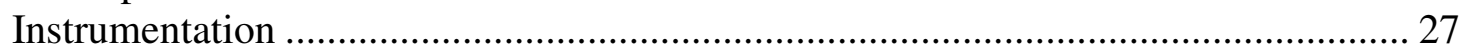

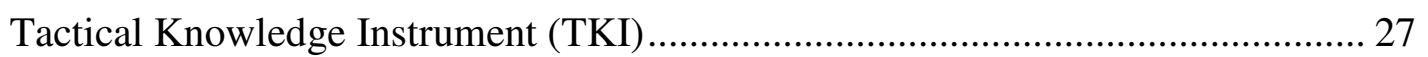

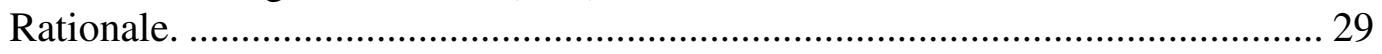

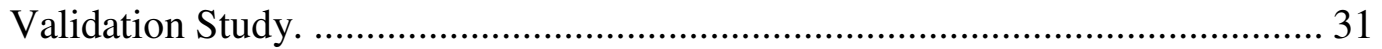

Game Performance Assessment Instrument (GPAI),........................................... 33

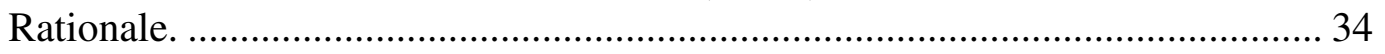

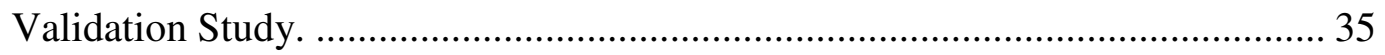

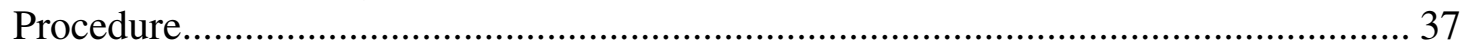

Tactical Knowledge Instrument .................................................................. 38

Game Performance Assessment Instrument........................................................... 40

\section{RESULTS}

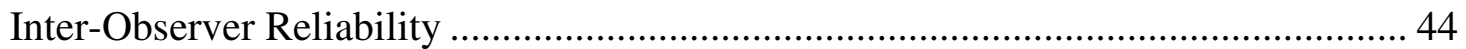

Differences in Overall GPAI and TKI Component Scores ........................................... 45

Relationship Between GPAI and TKI................................................................... 48

Expertise Level Impact on Tactical Knowledge and Performance.............................. 48

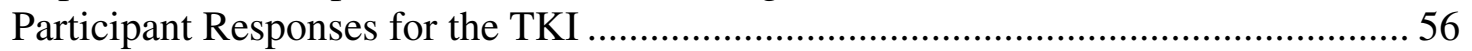

Participants' Movement Experiences.......................................................................... 60 


\section{DISCUSSION}

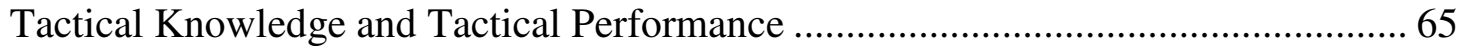

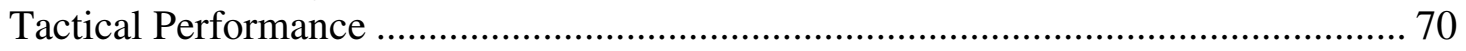

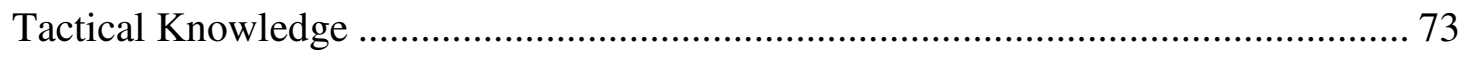

Responses to Participant Questionnaire ……………................................................. 80

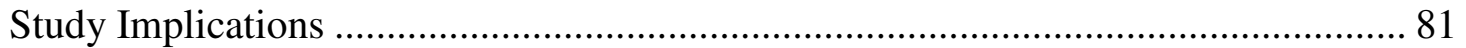

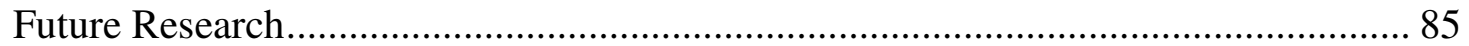

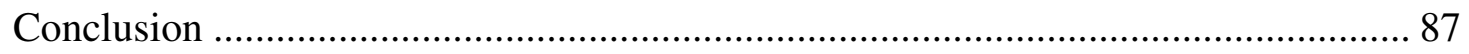

\section{APPENDICES}

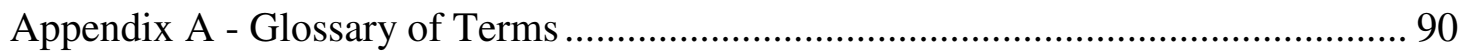

Appendix B - Tactical Knowledge Instrument (TKI) ................................................ 91

Appendix C - Game Performance Assessment Instrument (GPAI) ............................ 92

Appendix D - Participant Questionnaire ................................................................ 93

Appendix E - Consent to Participate in Research ........................................................ 97

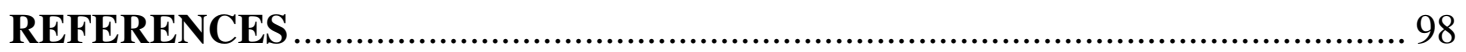




\section{LIST OF TABLES}

Table $1 \quad$ Sample $(n=34)$ Mean Scores and Correlated $t$ -

tests..............................................................

Table 2 Novice $(n=11)$ Mean Scores and correlated $t$-tests for the

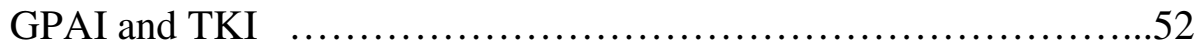

Table 3 Intermediate $(n=11)$ Mean Scores and correlated $t$-tests for the GPAI and TKI ............................................. 53

Table $4 \quad$ Expert $(n=11)$ Mean Scores and correlated $t$-tests for the

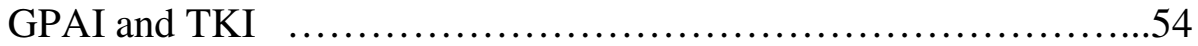

Table 5 Sample of the Common Participant Responses to the TKI Components......................................................

Table 6 Responses to Questionnaire - Lesson and Team Sport Emphasis........................................................ 


\section{LIST OF FIGURES}

Figure $1 \quad$ Lowest Proportional Scores.....................................49 
Introduction

\section{Statement of the Problem}

The purpose of this study is to explore how conceptual understanding is related to physical performance when participating in team sports. More specifically, the goal of the study is to determine if players' offensive off-the-ball tactical knowledge is positively correlated to their off-the-ball tactical performance during game play. This study also will investigate whether there is a significant difference in players' offensive off-the-ball knowledge and offensive off-the-ball performance depending on their level of expertise. In this study, expertise is referred to as the progressive level of proficiency players accumulate (from novice to expert) in their knowledge and performance of team sports.

This study will be limited to territorial or invasion type games where "teams score by moving a ball (or other projectile) into another team's territory and either shooting into a fixed target (a goal or basket) or moving the projectile across an open-ended target (i.e. across a line)" (Mitchell, Oslin, \& Griffin, 2003, p. 7). This study will focus exclusively on offensive off-the-ball movement, which is the movement executed when a player does not possess the ball. 
Hypotheses:

1. Territorial game players' off-the-ball knowledge scores are positively correlated to their off-the-ball performance scores.

2. Players at different levels of expertise (novice, intermediate, and expert) will have progressively higher mean scores on offensive off-the-ball performance.

3. Players at different levels of expertise (novice, intermediate, and expert) will have progressively higher mean scores on offensive off-the-ball $\underline{\text { knowledge. }}$ 


\section{Justification for Significance of the Study}

\section{Introduction}

Since most invasion/territorial games are played in an ever-changing dynamic environment, players need to independently "read" situations to make decisions, form a plan, and adjust to their opponents' movements. They should not be marionettes that only move when told to do so by someone else. Teacher dependence is counterproductive because effective invasion/territorial game players must be able to think on their own (Turner \& Martinek, 1995). When coaches and adults prompt or select the strategy for players, their ability to make decisions will be stunted (Thomas, 1994). Helping players recognize cues within the game provided by the movements of teammates and opponents should be the ultimate goal when teaching game play; it is not sufficient for players just to acquire techniques. Bunker and Thorpe (1983) strongly emphasized that helping players know what to do and when to do it are as valuable as assisting them in how to do it.

Traditionally, a technique-based approach has been employed when teaching or coaching team sports, which often produces players who can execute techniques but cannot effectively apply the appropriate technique in game contexts or make decisions on their own. Low-level game play is often the result. Therefore, the reason for selecting this problem to study is to add to the research base concerning effective games players.

When instruction focuses solely on motor skill execution and lacks tactical knowledge, performers will not acquire the needed game strategies to be competent (Nevett, Rovegno, \& Babiarz, 2001). Individuals may know what to do but are unable 
to exhibit good decision making for a variety of reasons such as time, opponent pressure, and anxiety (Turner \& Martinek, 1992). Some theorists believe techniques and tactics should not be separated. Both the cognitive and motor components are equally important in developing sport performance (Griffin, Dodds, Placek, \& Tremino, 2001). For example, one must consider the skill of passing and the tactic of off-the-ball cutting (movement when not in possession of the ball) to be relational. "Cutting and passing are inherently social, they derive their fundamental meaning from the game context, and the concept of the skill and a tactic should not be separated. A player's motor coordination is determined by the individual, environment and task constraints" (Nevett, Rovegno, Babiarz, \& McCaughtry, 2001).

"Playing well means choosing the right course of action at the right moment and performing that course of action efficiently and doing this over and over throughout the match" (Grehaigne, Godbout, \& Bouthier, 2001, p. 61). Therefore, effective game players must possess qualities that make it possible for them to perceive environmental stimuli surrounding them; make decisions to organize a plan of action depending on those stimuli; and then create appropriate movements according to the context of the game. Characteristics of effective play include: athleticism, knowledge of rules, knowledge of tactics, communication, fitness, technique, mental toughness and resilience, ability to "read the play" as well as anticipation (Piltz, 2003). Simply possessing the skills specific to the game may not always result in success. Thomas (1994) maintains that skillfulness does not always have a direct relationship with game performance. Players also must possess tactical awareness, which is the "ability to 
identify problems that arise while a game is in progress and to select the skills necessary to solve these problems" (Mitchell, Griffin, \& Oslin, 1994, p. 21).

Turner and Martinek (1995) defined a successful games player as someone who possesses the knowledge to make decisions in a timely and effective way. Light (2005) stated "good players so often seem to be in the right place at the right time. They seem to have more time than other players, and they always seem to make the right decisions. They often exhibit an 'uncanny sense of the game' "(p. 169). "Sport performance is a complex product of cognitive knowledge about the current situation and past events combined with the players' ability to produce the sport skill(s) required" (McPherson, 1994, p. 230). Kirk (1983) expresses the aim of teaching children to play games is to encourage them to perform intelligently. Effective games players go beyond collecting facts, they must draw connections to understand or accommodate the unfamiliar with the familiar. Kirk believes "one who performs intelligently has understood" (p. 44). It appears that the cognitive aspect of game play has a significant effect on players' overall performance, yet often, this facet of the game is not explicitly taught or explored.

\section{Relationship between Tactical Knowledge and Performance}

The demands of invasion/territorial-type games require players to be more than just skillful; game play is interwoven with many decision-making opportunities for participants. Adequate declarative knowledge (e.g., rules, positioning, objectives of the game) and perception are fundamental to decision making and must be formed before one can develop good decision-making skills (Turner \& Martinek, 1995). 
Skillfulness (the ability to properly execute sport specific techniques) does not always have a direct relationship to game performance (Thomas, 1994). Excellent technical players may not understand when and where to use the techniques. They may not know what to do in the context of a game situation (Turner \& Martinek, 1995). Thomas (1994) believes that game performance is divided into cognitive and skill components. Decision-making and knowledge make up the cognitive component, and skill is the actual motor execution. Grehaigne et al. (2001) make the connection between knowledge and skillfulness by stating that "any decision becomes valid only if it can be efficiently translated into action" (p. 61).

Co-dependence of skills and tactics was evident in a study using a modified threeversus-three aerial basketball game. Fourth grade students were assessed as to whether their tactical passing decisions and cutting actions changed, their ability to send catch-able passes to teammates improved, and if their skill in catching was enhanced after twelve lessons of an aerial (no dribbling) basketball unit (Nevett, Rovegno, Babiarz \& McCaughtry, 2001). Data indicate that participants significantly increased good passing decisions, from pre-test to post-test, which resulted in a significant increase in the quality of passes attempted. The number of lead pass attempts increased from $23.2 \%$ to $41.4 \%$, which put receivers in better position to decide on their tactical options. There was a reduced number of good held-ball (hold the ball instead of throwing it when a teammate is not open) decisions (13\% pre-test compared to $6 \%$ post-test). This outcome should be considered a positive result because there was more teammate off-the-ball movement, which provided better options for the passers so they did not have to hold on to the ball (Nevett, Rovegno, 
Babiarz \& McCaughtry, 2001). A reduction was seen in forced pass attempts $16.8 \%$ to $5.3 \%$ in the post-test results, and a lower frequency of "long bomb" (very long pass with a low completion rate percentage) attempts were tried: $8.3 \%$ to $2.9 \%$. Better passes were made because receivers were making more efficient and effective cuts to get open for a pass, resulting in a "higher percentage pass" being executed. Better decisions were being made by both the ball carrier and the off-the-ball teammates.

There was only one poor cutting action increase from pre-test to post-test $(7.3 \%$ to $14.8 \%$ ). This action saw more students moving into high traffic areas within the game, which reduced their chances of moving to an open space or receiving a pass. This may be due to multiple players continually coming back to support the ball carrier as opposed to standing still or running away from the ball carrier. This situation does indicate improved tactical awareness, but because players are moving into the same space, congestion occurs, reducing the effectiveness of the play.

Having the knowledge about what to do and actually executing the movement are not necessarily synonymous. "Knowing what to do and being able to perform in controlled contexts is related to being able to select an appropriate response and execute that response in game context" (Rink, French, \& Tjeerdsma, 1996, p. 409). Response selection is more important for highly tactical activities such as those in invasion/territorial games, especially off-the-ball movement, while response execution is vital for less tactical activities (i.e. net, striking/fielding or target games). The invasion/territorial games tend to be played in a more dynamic, ever-changing environment with a greater number of players involved, where the other types of games are considered more static, with less decision-making options at one time. 


\section{Expertise and Rate of Improvement}

Thomas (1994) states that expertise is more than the sum of knowledge and skill; experience is also a game performance variable: "experience might be the interaction of skill, knowledge and the psychological variables" (p. 201). French \& McPherson (2004) have reversed their conclusions of initial studies, which implied that knowledge increases more quickly than skill (French \& Thomas, 1987; McPherson \& French, 1991; McPherson \& Thomas, 1989). Results of the latest study indicate that knowledge and decision making develop more slowly than skill development.

However, it is still believed that both knowledge and skill increase with experience. Therefore, equal attention to knowledge development and improving techniques may enhance students' game performance in the future.

Factors that affect the acquisition of tactical knowledge and performance do not just center on the length of time they have to explore the concepts and control of the object, but also on the age, skill level, and experience level of the participants. The Nevett, Rovegno, Babiarz, and McCaughtry (2001) study separated students by experience level when analyzing the data collected for instruction in a three-on-three aerial basketball unit. The low-skilled group (L) made slightly more good passing decisions after participating in the 12-lesson aerial basketball unit than the high-skilled group $(\mathrm{H}): M \mathrm{~L}=66.9 \%, M \mathrm{H}=66.2 \%$, and they made more scoring attempts $(M \mathrm{~L}=$ $12.5 \%, M \mathrm{H}=10.5 \%$ ). This may be due to the higher-skilled students taking more risks and/or the lower-skilled group following teacher suggestions, which tend to be conservative. 
The lower-skilled players learned to be more active and made more effective cuts during game play. The standing (players not cutting into open space) scores from preinstruction to post-instruction for lower-skilled students were reduced ( $M=16.7 \%$ to $M=8.6 \%)$. The higher-skilled had a large decline in attempts of long bomb cuts from pre-instruction to post-instruction $(M=16.1 \%$ to $M=2.1 \%)$. This may reflect the higher-skilled students' ability to access more tactical options, and then to prioritize those options according to effectiveness, and to recognize where the open spaces are. The high-skilled group increased good cutting scores more than did the low-skilled group $(M \mathrm{H}=23 \%, M \mathrm{~L}=14 \%)$. Data analysis shows both groups improved; however, the experience level of the high-skilled group may have given these students better perceptual and decision-making processing ability. When comparing types of cuts, the high-skilled group increased the straight line cut somewhat better than did the low-skilled group $(M \mathrm{H}=17.3 \%, M \mathrm{~L}=14 \%)$. However, the low-skilled group increased their v-cuts $(M=5 \%)$, and the high-skilled group did not. V-cuts are easily mastered; therefore, most low-skilled players more often utilize this option, whereas higher-skilled players access more complex cuts. Since both groups demonstrated improved tactical performance, though not highly proficient, the time for cognitive processing was reduced. Enhanced processing resulted in an increase in the speed of decision-making and ultimately, more accurate decisions (Nevett, Rovegno, Babiarz, \& McCaughtry, 2001).

Graham, Ellis, Williams, Kwak and Werner (1996) studied high- and lowskilled badminton players participating in either a technical (emphasis on skills), tactical (emphasis on tactics), or combination (technical and tactical) instructional 
approach. Results suggest that while all students demonstrated positive achievement (higher scores on the post-test) on both skills and game play, the higher-skilled players performed better overall on all measures. In addition, the low-skilled performers had a higher percentage of negative achievement where they attained lower scores on the post-test in skill and game play categories. The quality of practice for the lowerskilled participants was hindered because of their lack of adequate preparatory movements, difficulty with force production for the skill, and continual practice with their less-skilled peers (Graham et al., 1996).

Expertise also was addressed in a study involving youth league baseball (French, Spurgeon, \& Nevett, 1995). A variety of skill, knowledge and game performance data were collected throughout a summer baseball season. A 3 x 4 (Expertise x Age) MANOVA using measures of experience, cognitive and motor skill components of game performance, revealed significant main effects. For expertise Wilks's lambda = $.60, F(18,190)=3.08, \mathrm{p}<.01$, and for age, Wilks's lambda $=.37, F(27,278)=4.22$, $\mathrm{p}<.01$. ANOVA for catching also revealed significant differences, $F(2,99)=11.54$, $\mathrm{p}<.01$. High-skilled players had a higher percentage of successful catches during game play than did the average- or low-skilled players. However, the analyses for age and expertise were not significant for game decisions. This evidence suggests that the "skill execution components contributed most to discriminating expertise but that cognitive components of performance contributed minimally to expertise" (French et al., 1995, p. 199). High expertise levels seemed to have a direct relationship with well-skilled or technically advanced players; however, players considered to have 
acquired high levels of expertise did not necessarily perform better when it came to the cognitive components of baseball performance.

Since decision-making and knowledge do not automatically develop as a player becomes more familiar with a game, children at all levels of expertise might benefit from early intervention of game tactics. If they are allowed to explore the movements necessary to enhance their on-the-ball and off-the-ball effectiveness, all children may become more competent game players.

\section{Assessment of Tactical Knowledge and Performance}

A comprehensive assessment of games player effectiveness requires the collection of skill, knowledge, and performance data. Griffin et al. (2001) maintain that both cognitive and motor components are extremely important in developing sport performance expertise. Blomqvist, Luhtanen, Laakso, \& Keskinen (2000) conclude:

"when assessing a player's game understanding, we learn something about the player's tactical knowledge but nothing about his or her ability to carry out the decisions in an actual game situation. Therefore, there is a need for multiple measures of game understanding and game performance that would give us more information about relationships between these concepts in order to develop and enhance students' game and sport understanding" (p. 336).

In order to evaluate a player's level of game play, all components that define an effective games player must be considered. Traditional assessment instruments in physical education include cognitive paper and pencil knowledge tests. These tests determine players' knowledge of rules, positioning, or mechanics of skills. A skills test is another typical assessment. Skill tests, where a technique is assessed in isolation (e.g. dribbling a ball through a row of cones for time or throwing a football at 
a target a fixed number of times) are used to show evidence of technique mastery.

However, neither is an appropriate, authentic assessment of performance within a game. If one wants to determine a player's tactical awareness and actual game performance, alternate assessment instruments must be considered.

Assessment to determine how effective players are during game play must include not only how well players perform sport specific skills, but also their declarative knowledge (e.g. rules and game positions), procedural knowledge (e.g. on the ball and off the ball tactics), and actual performance. Grehaigne, Godbout, \& Bouthier (1997) indicate that the current assessment practices in team sports include standardized setups (outside of game context) and real-life situations, which produce both quantitative and qualitative data. The data are collected by standardized skills tests; statistics derived from competition; and ratings of performance (the quality of form) in a standardized setup, or ratings of performance during the game.

It can be concluded that assessment of any given player in team sports involves a complex system. The intervening elements are not only numerous, but also interactive. The rapport of strength (oppositional relationship between teams) varies in different situations or even within one situation. Every play in a territorial game involves interactions between teammates and opponents; decisions concerning movement selection are based on this oppositional relationship. The members of a given team are interdependent; and it is possible to assess individual participants within the play of the team (Richard, Godbout, Tousignant, \& Grehaigne, 1999). These factors indicate that a multidimensional approach to authentic assessment may be essential. In team sports, performance is a result of the interaction of strategy, 
tactics, perceptual skills and motor skills (Grehaigne \& Godbout, 1995). Therefore, the emphasis on skills, knowledge, or performance (or any combination of these) will impact the selection of the appropriate tools.

Assessing knowledge.

It is essential to develop the cognitive aspect of game play in effective games players. Assessment of players' knowledge about a team sport can provide clues about what may be hindering their development and what intervention may aid in their understanding. To assess knowledge, one may not just observe players' performance in games to determine their decision-making proficiency and response selection ideas. "Game play assesses only the accuracy of the implementation of those ideas" (Rink, French, \& Graham, 1996, p. 499). Therefore, other methods need to be employed to assess knowledge.

Knowledge-assessment instruments in Physical Education may include paper and pencil tests used to find out students' knowledge of rules, positioning, or key parts of skills. Specifically, multiple-choice tests have been used as an assessment tool for judging sport knowledge in many research studies (French \& Thomas, 1987; French, Werner, Taylor, Hussey, \& Jones, 1996; French, Werner, Rink, Taylor, \& Hussey, 1996; McPherson \& French, 1991; McPherson \& Thomas, 1989; Nevett, Rovegno, \& Babiarz, 2001; Turner \& Martinek, 1992).

Another method used by researchers to evaluate knowledge involves the manipulation of game pieces to solve tactical problems in game situations. Interviews were conducted to investigate middle school students' current domain-specific knowledge of soccer and Pre-Service students' construction of tactical concepts before 
and after participating in a tactical course for invasion games (Griffin et al., 2001;

Howarth \& Walkuski, 2003). In the Griffin et al. study, participants were asked openended questions about seven offensive or defensive tactical problems (i.e. maintaining possession, attacking the goal, creating space in attack, using space in attack, defending space, winning the ball, and bunching up). Students were asked to move magnetic game pieces (representing offensive and defensive players) as they verbally described how they would solve the tactical problem. A scoring rubric was developed to measure the student responses as sound, feasible, or convoluted (inter-observer reliability $=.92)$. The Howarth and Walkuski (2003) study concentrated on one tactical problem (bunching up) for a pre- and post-test. Participants were asked to "explain how they would describe the play/tactics of the particular scenario to naïve high school physical education students" (p. 8). Their responses were scored on a rubric, which assessed the level of verbal solutions (ranging from not recognizing the tactical problem to a rich description of a global solution), the extent of manipulation of the markers (ranging from no manipulation to three-or-more moves made), the tactical conception of the scenario (choice of a one-sided focus on offense or defense to two-sided focus of both offense and defense), and the reasons given for their selected solution (choice of no reason, incorrect reason, or correct reason).

Video analysis has been a source for assessing tactical knowledge. French, Werner, Taylor et al., (1996) used video to detect tactical errors after observing a segment of badminton play. Students were asked to write responses (after watching the videotape) to three questions: 1. "What mistake did player [A or B] make?" 2. "What should Player [A or B] have done?" 3. "Why should he or she have done this?" 
Responses were scored at three levels: no information/misinformation, general or specific.

Blomqvist et al., (2000) developed a basic or novice-level video-based gameunderstanding test procedure. Students watched a badminton singles point played out on video (a total of 19 different sequences); then viewed a still frame of the situation where one player was getting ready to play the next stroke. Lastly they were shown a diagram of the situation with three possible stroke responses. After this process, students were given a list of ten arguments and instructed to select two to give as reasons why they chose their solution. Blomqvist et al. suggest the advantage of this tool is that it is easy to administer, large groups can be tested at the same time, basic tactical skills can be taught through the video sequences, and students can be taught to notice differences between offensive and defensive strategy. However, video scenarios for other sports presently are not available; therefore, instructors will have to develop them prior to administering this type of assessment.

Researchers also use situational interviews as knowledge assessments. French and Thomas (1987) conducted open-ended interviews for players in basketball leagues for eight-to-10 year olds and 11-to-12 year olds. Players were instructed to provide a written list of appropriate actions for five situations: 1. offensive actions for a two-onone fast break; 2. offensive actions in a three-on-two fast break; 3 . defensive actions on a three-on-two fast break; 4 . offensive out-of-bounds plays; 5 . possible ways to score a field goal on offense. The quality of responses for situations one through three were coded as 0 (no correct answers), 1 (correct answers given without demonstrating complete understanding), or 2 (complete understanding by explaining answers in 
context and reference to oppositional action). Situations 4 and 5 were coded as a 0 (responses were based on simple passes) or 1 (systematic movement of the players and the ball).

McPherson and Thomas (1989) assessed current tennis knowledge and Nevett, Rovegno, \& Babiarz, (2001) concentrated on passing and cutting knowledge in invasion/territorial games by implementing a situational interview. The authors examined tennis knowledge by determining what players knew about service, backcourt and net play. The questions were written out and verbally stated by the examiner. Players also had a diagram of the scenario at their disposal. Players gave a verbal response to each question.

Examiners, by evaluating the responses to a series of questions, assessed passing and cutting knowledge (i.e." Your team has the ball in a game like basketball or soccer, and you are trying to score. You have the ball in your hands. Tell me all the things you think about when you have the ball."). Students gave verbal responses, which were recorded for coding purposes. Each concept was coded according to the quality of the response in context to the situation.

Studies have shown that declarative knowledge can be assessed effectively through a multiple-choice test or by describing the skill questions. The design of quality tests and finding the time to administer them may be problematic. However, useful data leading to objective evaluation can provide evidence for instructional accountability. Procedural knowledge assessments (game board, video analysis, and situational interviews) produce data about a players' tactical understanding. It will give instructors an idea about how players process information and if there is 
comprehension of what must be done in a game situation. This can be time consuming; an effective method and rubric must be clearly defined in order to gather this valuable information.

\section{Assessing performance.}

Game performance instruments assess how players combine skills and knowledge to produce their movement in games. Not only does a player need to execute the sport specific skills and access declarative as well as procedural knowledge, he or she must know when and where to use them at the appropriate time within a game setting. When assessing game understanding, "we learn something about the player's tactical knowledge, but nothing about his or her ability to carry out the decisions in an actual game situation" (Blomqvist et al., 2000, p. 336).

Observational assessments (both live and video-taped) are common tools used to determine game performance. Various formulas and coding systems have been developed to determine performance scores. Point interviews occur after a point is played out in tennis, when an evaluator asks a player why he or she selected a certain movement. The responses are used to access how a player processes information.

Youth baseball performance was tracked by videotaping a minimum of five games for each participant throughout the season. Two game components were evaluated: batting and defensive game play. Two coders with extensive experience in baseball (inter-observer reliability above .90 ) observed the video to determine batting average and percentage of ball contact. They recorded the number of foul balls, missed ball swings, walks, and type of hit (e.g. ground ball, pop up) to measure ball contact. 
Video analysis of defensive plays was coded for everyone who should have been involved in the play (French, Spurgeon, \& Nevett, 1995).

Several other studies (French \& Thomas, 1987; McPherson \& Thomas, 1989; McPherson \& French, 1991; Turner \& Martinek, 1992; French et al., 1995; French, Werner, Rink et al., 1996; Nevett, Rovegno, Babiarz, McCaughtry, 2001) employed a coding system to assess game performance for individual and team sports. Various game components (positioning, control of the ball, decision making, and skill execution) were measured as students participated in the game. Each study developed individualized coding systems to distinguish between successful and unsuccessful criteria. For example, Nevett, Rovegno, Babiarz, and McCaughtry (2001) coded Passing Decisions: 0 (poor decision) and 1 (good decision), or Length of Pass: 1 (appropriate length), 2 (too short), and 3 (too far).

Point interviews were instruments of choice for badminton (French, Werner, Taylor et al., 1996) and tennis (McPherson \& Thomas, 1989) game performance. Probe questions such as "what strategy did you use on that point?", "did you hit any shot especially well or poorly during that point?", and "what strategy are you going to use on the next point?" were asked after a point for both sports. Special attention was given to ensure that subjects were questioned quickly so the verbal reports did not affect performance. Once players completed a point, they went to the side of the court where audio- and videotape recorders captured their response to a question that was written on an index card and taped to the court. A coding system, classified responses according to how specific or general they were. French, Werner, Rink et al. (1996) realized some problems with their interview process. Examiners were not consistent 
about asking the same questions after each point or to each player. They also asked questions that were leading or too general in nature, which affected the validity of the results. While all of these coding systems revealed important data about game performance for on-the-ball tactics or general off-the-ball movement, very few, if any, assess the specific off-the-ball tactics that players choose to execute while engaged in the game.

The Game Performance Assessment Instrument (Oslin, Mitchell, \& Griffin, 1998) has been developed to address players' off-the-ball movement during games in educational (physical education) and sport settings. Instructors make the decisions about what criteria to observe depending on their point of emphasis throughout a unit of time. Actual game play has been assessed through the collection of objective data on student performances without relying on standardized tests, which do not take opponent and teammate movement into consideration.

The Game Performance Assessment Instrument (GPAI), an objective analysis of all types of games, addresses on the ball skills and off the ball movements (Oslin et al., 1998). The GPAI is "designed to provide teachers and researchers with a means of observing and coding performance behaviors that demonstrate the ability to solve tactical problems in games by making decisions, moving appropriately, and executing skills" (Mitchell, Oslin \& Griffin, 1995, p. 40). Implementation of the GPAI also can take the form of a rating scale (1-5) or rubric, or a tally system. The tally system is recommended for striking/fielding games (i.e. baseball, cricket) or net/wall games (i.e. tennis, volleyball) because of the more-frequent stoppages of play such as after a point or play. Calculations are made using the GPAI to measure game involvement and 
game performance for seven different game components (base, adjust, decisions, skill execution, support, cover, and guard/mark). The rubric scoring system is recommended for the invasion/territorial games due to the ever-changing environmental factors and very short stoppages of play.

Preliminary results on the GPAI indicate content and construct validity. Six experts were asked to provide feedback about the GPAI components; terms and definitions were revised until the experts reached consensus for content validity. Construct validity was measured by the success of the GPAI to distinguish between high and low performers. Significant Effect Sizes (ES) were present for six of the nine GPAI components tested for soccer $($ decisions $=1.19$; skill $=1.93$; support $=$ $1.31)$, basketball $($ decisions $=.64 ;$ skill $=1.64 ;$ support $=.50)$, and volleyball $($ decisions $=1.50 ;$ skill $=1.58 ;$ adjust $=.23)$. Inter-observer reliability $($ soccer, $.81 ;$ softball; .86 and basketball, .83$)$ and test-retest reliability (.80) also were compelling for the components tested (Oslin et al., 1998).

"Performance tests often test students on something that is completely unrelated to successful game play" (Veal, 1992, p. 90). As an example, participants may be given an isolated skills test or have statistics kept from practice sessions, neither of which represent how they perform in actual game competition. Inaccurate conclusions about level of performance could be drawn using this type of data. "Measures of performance taken during game play provide a more accurate representation of a player's or student's ability. Furthermore, these measures are more authentic, because they occur within the context of the game. Measures of off-the-ball movement corroborate whether a student fully understands his or her role as a supporting member 
of a team and need to be included in student evaluations of game performance" (Oslin et al., 1998, p. 240).

It must be cautioned however, that observational assessment tools must take into consideration the number of players on a team, the time allotment of play, and the type of game played, so players have adequate opportunity to make decisions and act on those decisions. Some tactical situations do not occur within the measured span of time, so students may not attempt certain moves or skills in their repertoire or one tactic/skill may be working, so others might not be performed; therefore, a performance score may not be a true indication of his or her performance potential. Rink, French, and Graham (1996) also caution that "observational instruments must be tailored to the specific offense and defense" and "should reflect what was taught" (p. 501).

As stated earlier, most of the current performance assessments focus on the player with the ball, while very few address off-the-ball movement. This important aspect of game play cannot be ignored; in a 90 minute territorial game (ball in play for 60 minutes), a player is in possession of the ball for only two to three minutes (Light, 2005). The other 57-to-58 minutes are spent making decisions about where and when to move to be in a help position. Assessment must be available to determine the effectiveness of players' off-the-ball decisions. The game board studies (Griffin et al., 2001; Howarth \& Walkuski, 2003) for tactical knowledge assessment and the GPAI (Oslin et al., 1998) have the potential to record off-the-ball tendencies. They also are authentic assessments as the components, and criteria chosen are specific to what has been taught or what is being researched. 
A review of theories and research into effective game play suggest that instruction in skill development cannot be the sole focus when teaching games. The cognitive aspect of knowing when, where, and why to select--then execute--a skill has equal importance. Also, the research has concentrated almost exclusively on a player's movement when he or she has the ball versus what a player does without the ball. This on-the-ball emphasis also is present in instruction of children in sport and educational settings. The development off-the-ball movement is vital because the majority of time playing a game is spent supporting a teammate, creating or defending space, and trying to elude an opponent.

After recognizing the importance of cognitive functions in game play and off-theball movement, this study will serve to further advance the research in this area. This research study will investigate the relationship a player's tactical knowledge has with that player's actual performance in a game setting. This study also will explore the impact a player's level of expertise in playing invasion/territorial games has on both his and her tactical knowledge and tactical performance, specifically with his or her off-the-ball movement. Results of this study could give insight into the teaching and coaching methods that best suit the teaching of games in order to develop more effective players. 
Method

Participants

The study attempted to control for gender. Therefore, only female students were selected to participate. The rationale for selecting female participants was that there was a better chance of representing all team sport expertise levels for females versus males. The researcher was concerned that a pool of male students would be heavily weighted in favor of advanced and highly skilled athletes as opposed to novice level participants. This was the case in a validation study conducted by the researcher in February of 2004. With a relatively small sample size $(n=34)$ for this dissertation study, it was imperative that the whole spectrum of expertise levels be present and clearly distinguishable to conduct a valid test of the hypotheses.

Participants for this study were selected from Rhode Island College students who had not taken PED 207 (Motor Skill Development for Life: Wellness I). PED 207 introduces tactical concepts for team sports, which might influence the results. The researcher was interested in the participants' current knowledge and performance without the intervention of a tactics course.

Female students were recruited from PED 132 (Beginning Gymnastics), PED 140 (Introduction to Movement Sciences), PED 205 (Conditioning for Personal Fitness), PED 208 (Motor Skill Development for Lifetime Wellness II), PED 346 (Methods and Materials in Elementary Physical Education and Health Education), HED 101 (Human Sexuality), HED 102 (Personal Health), and HED 115 (First Aid/CPR) during the fall semester in 2005. Classes the researcher taught were not considered in the recruitment of participants for the study. These courses were selected because they are open to all 
students and include students who have not been accepted into the Health and Physical Education Department of the Feinstein School of Education and Human Development (e.g., PED 346 is a methods course for elementary education majors and HED 102 is a personal health class offered to the whole college community). This was done to achieve a more diverse sample and to assure that participants represent a varied expertise and experience level.

The researcher went to each class to introduce the project. Students were told the objective of the study was to evaluate assessment tools; therefore, it was imperative (to be considered a good scoring system) that the instruments be valid for a wide range of skill levels. For the study to be successful, it was necessary to have all levels of expertise and experience represented. Students were told they would be helping in the investigation of a new area of game performance and knowledge assessment, as there has been little research into precise rating systems.

The researcher then distributed study packets to female students enrolled in those classes. The following information was included in each study packet; a cover letter (explaining the study, requirements for participants, and contact information); two Consent to Participate Forms (one to return and one to keep for their records); and a Participant Questionnaire. Potential study participants were instructed to complete the questionnaire and one of the Consent to Participate Forms; then return them to the Rhode Island College Health and Physical Education Department Secretary prior to the deadline date of September 9, 2005.

A total of 36 participants (12 novices, 12 intermediate and 12 experts) were chosen from those volunteering to participate. The researcher went to 12 classes and 
requested participation from approximately 180 female students. Forty-five packets were returned to the researcher (25\%). All 45 volunteers were given instructions for the data collection day. The researcher anticipated some volunteers canceling after initial confirmation of their participation, which did occur (11 of 45, 24\%, withdrew) resulting in 11 novices, 11 intermediate, and 12 expert participants completing the two instruments. The participants represented a variety of undergraduate majors including: Business Management $(n=1,3 \%)$, Chemistry $(n=1,3 \%)$, Community Health $(n=2$, $6 \%)$, Elementary Education $(n=4,11 \%)$, Elementary Education/ Special Education ( $n$ $=5,15 \%)$, Psychology $(n=2,6 \%)$, Physical Education $(n=17,50 \%)$, Secondary Education $(n=1,3 \%)$ and Special Education $(n=1,3 \%)$. Even though a large percentage of participants were physical education majors they were all in the very beginning stages of their professional preparation program. None of the physical education majors had been accepted into the Feinstein School of Education and Human Development, which indicates they were intended majors in the first few semesters of the program. Therefore being a physical education major had little impact on their tactical knowledge and tactical performance in this study.

The questionnaire ascertained students' experience and expertise in a variety of team sports. Participants were classified as novices if they met any of the following criteria:

1. did not play team sports at all;

2. only played team sports on a club/youth league team;

3. only played team sports with friends or family in an unorganized setting (e.g., backyard or pick up games);

4. only played team sports in Physical Education class;

5. only played nonterritorial interscholastic sports (e.g. volleyball, softball, track \& field). 
Participants were classified as intermediate if they met either of the following criteria:

1. played at least one organized interscholastic territorial game;

2. any intercollegiate team sport (e.g., volleyball, softball).

Participants were classified as expert if they met both of the following criteria:

1. played at least two territorial games at the interscholastic/intercollegiate level or one collegiate territorial and one collegiate non territorial team sport;

2. played at least three years in at least one territorial sport as a starter or regular substitute.

Nine of the 11 novice participants reported no experiences in territorial games beyond what they were introduced to in Physical Education class. They did not play interscholastic or intercollegiate sport. The remaining two participants took part in gymnastics and track/field (nonterritorial sports) at the high school level.

Two of the intermediate participants reported to have played just one sport; one played a territorial sport at the high school level (basketball) the other a nonterritorial sport at the interscholastic and collegiate level (volleyball). The remainder of the intermediate participants $(n=9)$ played more than one sport. They reported participation in at least one territorial sport (basketball, field hockey, soccer) and a nonterritorial sport (cross country running, softball, tennis, volleyball). Four intermediate participants did not play intercollegiate sport, while the remaining seven participants played intercollegiate volleyball (nonterritorial).

All of the expert participants $(n=12)$ played three to four years of interscholastic and/or intercollegiate sport as a starter or regular substitute. All experts played at the intercollegiate level (Division III), with eight participating in a collegiate territorial sport (basketball, ice hockey, lacrosse, soccer) in addition to multiple interscholastic sports. Four experts reported playing at least one territorial and one nonterritorial 
interscholastic sport, as well as playing a nonterritorial intercollegiate sport (softball, volleyball).

\section{Instrumentation}

The goal of this study was to determine if there is a relationship between players' knowledge and actual performance of off-the-ball movement in a territorial game with players possessing different expertise levels. In order to measure these variables, two instruments were used. One assessed participants' knowledge of off-the-ball movement, using one of the seven tactical scenarios developed for studies by Griffin, Mitchell, and Oslin (1997) and Griffin et al. (2001). For the purpose of this study, this instrument will be referred to as the Tactical Knowledge Instrument (TKI). The TKI is a modification of the Tactical Concepts Knowledge Rubric used in the study by Howarth and Walkuski (2003). Participants' performance of off-the-ball movement during a game situation was assessed using the Game Performance Assessment Instrument (GPAI) developed by Oslin et al. (1998).

\section{Tactical Knowledge Instrument (TKI)}

The TKI scores a participant's response when asked to solve a tactical problem in a territorial game. The tactical problem was shown on a magnetic game board with moveable colored game pieces representing two opposing teams of three players each. Players were first asked to verbally identify the tactical problem, then verbally describe how to solve the problem while simultaneously moving the game pieces to show where and when each game piece should be placed. Players' responses indicate the depth of their knowledge of what to do in a typical game situation. The participants' responses were videotaped and scored at a later date using the TKI 
rubric. The scoring rubric scores players' responses on: 1. their verbal solution to the problem; 2. their manipulation of the game pieces; 3. their recognition of offensive as well as defensive movement; 4. their rationale for the solutions provided.

A global solution is the identification of the tactical problem in the most broad and general terms. For example, if a scenario depicts all players on the same side of the field, a player might say that there is a need to "spread out." However, they do not offer more specific information such as "the players need to be sure they are using all of the playing space, they need to take their defenders with them, and they have to look around to see where their teammates are moving." The latter represents a more rich description when solving the tactical problem. The offense/defense interplay indicates whether the players recognize only offensive teammate movement (onesided focus) or if they also describe what the defensive opponents do as a result of the offensive movement (two-sided focus).

The depth of their verbal solution will range from not recognizing or incorrectly identifying the problem ( 0 points) to offering a rich description including several possible solutions ( 3 points). Physical manipulation of the moveable game pieces (markers) will range in score from no manipulation ( 0 points) to reflecting the correct overall solution that encompasses four or more different moves ( 3 points). The offense/defense interplay will indicate whether the player used a one-sided focus (offensive or defensive) to solve the tactical scenario (1 point) or two-sided focus offensive and defensive ( 2 points). The rationale for participant's solutions will range from no reasons given ( 1 point) to correct reasons given ( 3 points). Overall scores for 
the TKI ranged from 1-12 points. The rubric for scoring Tactical Knowledge can be found in Appendix B.

\section{Rationale.}

To determine tactical knowledge with the TKI, the researcher chose the tactical scenario of "maintaining possession of the ball" because of research conducted on middle-school students' current knowledge of soccer. In the Griffin et al. (2001) study, tactical offensive situations were easier to respond to. The authors reported, "more participants were able to solve offense oriented scenarios, while fewer were able to solve the defense oriented scenarios" (p. 326). Therefore, in order to investigate expertise of off-the-ball movement, the chosen scenario needs to be one that players from novice to expert can successfully identify and solve. The accuracy, validity, breadth, and depth of the participants' responses were to be the distinguishing factors.

The offensive scenario was chosen according to the findings of the Griffin et al. (2001) study. The researcher agrees with the findings of French et al. (1995) that there should not be a significant difference in how participants of various ages respond to tactical scenarios. Their analyses indicate that there was not a significant difference, based on age, related to players' game decisions. Therefore, responses of the participants in this study should be consistent with the findings for middle-school age participants. Novice players are still novices whether they are 10 years old or 20 years old.

French and McPherson (2004) also compiled data from previous baseball and tennis studies (McPherson \& Thomas, 1989; McPherson \& French, 1991; French et 
al., 1995) to present their findings concerning how novice and expert performers access tactical knowledge. Results indicate that youth and adult novices access similar information during game play. The studies revealed that both youth and adult novices attended to irrelevant conditions. "Most of the conditions attended to by youth and women novices were related to some characteristic of their own game play. Rarely did novices attend to their opponent, environmental conditions, and player position on the court." In addition, "these novices did not use encoding and retrieval strategies to diagnose opponents' strengths, weaknesses, or tendencies as competition progressed" (p. 412).

Findings also indicate that "youth novices rarely mentioned the success or failure of response selection or motor execution. Women novices did produce some regulation of skill execution, but did not access verbal labels for correction of errors" (pp. 412-414). French and McPherson (2004) also report that novice youth and female players accessed limited actions (response selection) while "youth experts accessed a frequency of actions similar to that of female experts" (p. 412).

Even though "maintaining possession" had the lowest mean rubric score of the offensive scenarios, it deals more directly with off-the-ball movement, while the others (attacking the goal, creating space in attack, winning the ball, and using space in attack) emphasize on-the-ball skills. The inter-observer reliability for the tactical scenario rubric was .94 in the Griffin et al. (2001) study. The authors concluded, based on their results, that tactical scenario problems appeared to provide a "reasonable way to access participants" conceptions of tactics" and "this methodology is well suited to drawing out particular forms of student knowledge" (p. 339). 
To score tactical knowledge, this study will use a variation of the rubric developed for research conducted by Howarth and Walkuski (2003) when solving the same tactical scenarios as Griffin et al. (2001). Changing the rubric was necessary in order to compute a score for tactical knowledge, which was not the focus of the originators. The authors of the original rubric have not field tested the reliability of the instrument. However, this author conducted a validation study to determine inter-observer reliability of the modified rubric (TKI).

\section{Validation study.}

Twelve participants were asked to solve a tactical problem (maintaining possession) that was displayed on a magnetic game board. They were to verbally describe the problem and give all potential solutions they could think of by manipulating game pieces on the game board. Each participant was given the exact same tactical problem, directions about what to do, and the same prompts from the research assistants. Two experts, with extensive experience in teaching and coaching team sports scored the videotaped response of each subject. The researcher and the two experts reviewed the scoring rubric for clarity and scored a sample videotape together to further discuss and develop precision in using the instrument. The experts then scored each participant independently.

Participants were college-age male students enrolled in Health Education or Physical Education classes in the spring of 2004. Students were classified as novice ( $n$ $=6)$ and intermediate $(n=6)$. They volunteered to participate in the validation study by responding to the researcher's announcement read by their instructors in Health Education and Physical Education classes. The validation study was conducted with 
male participants, while the actual study used female participants. The researcher does not believe gender will make a difference in the reliability of the TKI. The researcher will test inter-rater reliability for the female subjects of this study in addition to statistical analyses of the hypotheses.

Statistical analysis revealed there was a linear relationship between the overall TKI rubrics scoring for the two experts coding the tactical game board scenario. There was adequate inter-rater reliability between coder's scores, $r(10)=.84497, p=.0005$. Also, three of the four components scored by the experts on the TKI showed adequate inter-rater reliability: the Verbal Solution $r(10)=.75147, p=.0048$; Manipulate Solution $r(10)=.73497, p=.0065$; and Reason for Solution $r(10)=.72559, p=.0076$. The Offense/Defense Interplay did not show a linear relationship $r(10)=.40291, p=$ .1941. As a result of these analyses the researcher consulted with the experts coding the rubric and modified the components to establish more clarity and distinction between rubric criteria. These changes are reflected in the present TKI rubric.

The experts rescored the same participants' videotapes using the revised TKI prior to data collection for this study to establish greater reliability or further revise the instrument. Statistical analysis revealed a higher inter-rater reliability from the first scoring attempt. There was a linear relationship between the overall TKI rubric scores for the two experts when they recoded the tactical game board scenario. There was a significant inter-rater reliability between coder's scores, $r(10)=.85099, p=.0004$. Also, three of the four components scored by the experts on the TKI indicated a significant inter-rater reliability: Verbal Solution $r(10)=.81650, p=.0012$; Offense/Defense Interplay $r(10)=.75593, p=.0045$ and Reason for Solution $r(10)=$ 
$.72559, p=.0022$. The Manipulate Solution had a moderate inter-rater reliability

$r(10)=.55015, p=.0638$.

Game Performance Assessment Instrument (GPAI)

The GPAI is an authentic assessment tool because instructors or evaluators determine the components to focus on and develop the criteria based on their teaching or evaluation goals. Because offensive off-the-ball movement is being emphasized in the study, the GPAI components are: 1. Decision Making - "choosing a movement or skill to execute a response to a tactical problem"; 2. Support - "players without the ball must be ready and available to receive a pass"; 3 . Adjust - "player's ability to make adjustments in positioning as needed in the game, they do not stand rooted in the game" (Mitchell et al., 2003, pp. 153-154).

Each component has criteria for the evaluators to look for as they watch the videotape of the game being played.

Decision Making

The player:

- determines that she is not in an open passing lane and moves into an open space;

- cuts into space vacated by a teammate or moves to another space so a teammate can cut into her space (synchronized movement with teammates).

Support

The player:

- comes back or lateral to support the player with the ball to receive a short possession pass (avoids a 10 second count) when her teammate is in trouble;

- moves to open space toward the target area at the appropriate angle. 
Adjust

The player:

- after she passes, she moves into a new space;

- tries to elude (dodge or fake) the opponent prior to cutting into space;

- moves to meet the pass.

This study will use a 5 point scoring rubric. Because of the continuous, quick flow of action, it would be impossible to record all off-the-ball movements in "real time" during the game. Each evaluator will watch a videotape of the game; then determine a rubric score for each of the criteria.

The GPAI scoring rubric is as follows:

5 = Almost Always - very few missed opportunities $(<10 \%)$

$4=$ Usually - consistently takes advantage of the opportunities $(61 \%$ $90 \%$ )

$3=$ Inconsistently - takes advantage of, but also often misses the opportunity $(40 \%-60 \%)$

$2=$ Usually Fails - misses opportunity more times than not $(39 \%$ $10 \%$ )

$1=$ Almost Always Fails - hardly ever takes advantage of the opportunity $(<10 \%)$

The rubric for scoring Tactical Performance can be found in Appendix C.

\section{Rationale.}

The GPAI was “developed as a comprehensive assessment tool for teachers to use and adapt for a variety of games" (Mitchell et al., 2003, p. 152). The GPAI (Oslin et al., 1998) evaluates all facets of game play, including off-the-ball movement. There are seven components to be chosen from when implementing the GPAI: base, decision-making, skill execution, support, mark/guard, cover, and adjust. Components are selected by what type of game is being played (invasion or territorial, wall/net, 
striking/run, or target) and what is to be evaluated (offense, defense, skills, or off-theball movement).

This instrument was used to determine the level of performance for each participant as she plays a three-on-three directional keep-away game. This throwing and catching game was selected because most children, by the upper elementary school grades, have a good grasp of these fundamental manipulative skills (Mitchell et al., 2003). Therefore, participant's skill level will not be as great a limitation. The constraint of not being able to run with the ball allows the focus to be on passing, receiving, and movement to support teammates instead of on-the-ball skills, such as dribbling or running with the ball (Mitchell et al., 2003).

\section{Validation study.}

The researcher also field tested the GPAI with the same twelve participants and expert scorers used for the TKI. Participants were divided into two groups to play a three-versus-three directional keep-away game (a score is recorded when the ball is passed down the court and over the end-line to a teammate who catches the ball in the air). The same expertise criteria described previously were used to divide the participants $(n=12)$ into novice $(n=6)$ and intermediate $(n=6)$ groups. Each game was videotaped so all players could be seen throughout the contest.

The experts reviewed the GPAI components and scoring criteria with the researcher for clarity, then scored a sample game (not with the participants of the actual study). The experts compared the scores and discussed discrepancies in interpretation; consensus was achieved for what the instrument components 
represented. The experts then viewed the videotapes, concentrating on and scoring one participant at a time.

Results for the validation study conducted by this researcher to establish interobserver reliability indicate a moderate linear relationship. Pearson $r$ statistics indicate an adequate relationship $r(10)=.62792, p=.0288$ for the overall GPAI scores of the two experts in the preliminary study. When the components were analyzed separately, a significant linear relationship was observed for decision making - open space scores, $r(10)=.74239, p=.0057$; support - forward movement into appropriate space, $r(10)=.84515, p=.0005$; adjust - moves into space after a pass, $r(10)=.64715, p=.0229$.

As a result, the scoring system was simplified and clarified to help the experts distinguish between score options. The experts rescored the participants' videotapes using the revised GPAI to establish greater reliability or further revise the instrument. The second attempt did not produce a significant increase in inter-observer reliability, which resulted in the researcher and coders clarifying the meaning of the components and confirming what to expect when selecting from the criteria.

A third scoring of the GPAI produced a higher inter-observer reliability. The Pearson $r$ statistics indicate an adequate relationship $r(10)=.76451, p=.0038$ for the overall GPAI scores of the two experts in the preliminary study. Once again when the components were analyzed separately, the only significant linear relationship observed was for the adjust - eluding a player before cutting, $r(10)=.59409, p=.0417$; and there was a trend-level relationship for the adjust - moves into space after a pass, $r(10)$ $=.53033, p=.0761$. Even though the overall GPAI had a higher inter-observer 
reliability for this validation study, the actual study will analyze the GPAI at a deeper level by having the expert coders review the videotaped sessions together after independent scoring to come to consensus on scoring discrepancies.

The validation study was conducted with male participants and this study will use female participants. The researcher does not believe gender will make a difference in the reliability of the TKI. The researcher will test inter-observer reliability for the female participants of this study in addition to statistical analyses of the hypotheses.

\section{Procedure}

Students who agreed to participate in the study were classified according to expertise, which was determined from the Participant Questionnaire (Appendix D). On the day of data collection, one participant contacted the researcher to say she was unable to take part in the study due to illness and another participant failed to arrive. This reduced the sample size to 34 participants (11 novice, 11 intermediate and 12 expert). The researcher had a substitute in reserve to participate in the novice and intermediate games so a three-versus-three game could be played. The substitute had a similar experience and expertise level to that of the novice and intermediate groups with whom she played. The substitute had previously completed PED 207 so her scores on the TKI or GPAI were not added to this study. The researcher does not believe that the substitute significantly contributed to or detracted from the game play of the other participants.

Prior to the data collection day, participants were contacted by telephone to remind them of the test date and give them information about arrival time, what to wear, what to bring, and where to meet. The procedure took approximately 1.5 to two 
hours per group, and the exact protocol was administered each time. Each expertise group was assigned a different reporting time to assure that the previous group would not interact with the next to be tested.

The researcher reviewed the objective of the study and gave an overview of the study's procedures to the participants. She then read the Consent to Participate form (Appendix E) to the study participants. The researcher also presented a "parking tactical problem" to familiarize the participants with what they will be asked to do on the TKI. Participants were asked what needed to be done to get to class on time (tactical problem) when they arrive on campus the first day of classes and see a full parking lot just minutes before their ten o'clock class. They were then asked what different options (tactics) they might use to secure a parking spot (e.g., sit and wait, drive up and down the rows, follow a student going to his/her car) and why they would use these options.

At this time, all participants waited in a holding room with a research assistant until escorted individually to a classroom to solve the tactical problem on the game board. Participants were then escorted to another monitored holding room until they were brought to the gymnasium to prepare for the game play portion of the study. At no time were participants allowed to observe the protocol for the TKI or GPAI. They were instructed not to talk with other participants about the study.

\section{Tactical Knowledge Instrument}

The knowledge component was addressed by administering the "maintaining possession of the ball" scenario to all participants. Each participant was asked to solve the same tactical scenario by moving the game pieces, describing the moves 
they made, and providing their rationale for making those moves. Each session was conducted individually in an empty classroom. The game board was on a table, and the participants were given the following directions (verbal and written):

"These magnets represent players in a game situation. You are on the blue team and the red team is your opponent. The black dot is the ball. Consider the boundary to be the edge of the white board. The purpose of this game is for your team to keep possession of the ball for two minutes while your opponents, who are playing man to man defense, try to take the ball away. The players without the ball can move anywhere in the boundary and the player with the ball can pass to a teammate or dribble the ball with the hand. The player with the ball has only 10 seconds before she must give the ball to a teammate."

1. "Before I allow you to manipulate the game pieces, what needs to be done by your team to solve this game situation?"

Let them respond to this question then ask:

2. "Show me by moving the game pieces and verbally tell me all the different options your team has to keep the ball away from the defense. Also tell me why you would make these moves. Take your time and tell me when you are finished."

Each session was videotaped; then scored by two experts in the field who have 23 years and 36 years of experience in teaching physical education and coaching team sports. The experts were also responsible for scoring participants in the validation study. After observing the videotape, the experts assigned a rubric score to rate each participant's tactical knowledge. The TKI scoring rubric was used to assess the participants' moves with the markers, solutions, and reasons for the moves. 


\section{Game Performance Assessment Instrument}

Participants played an eight-minute directional keep-away game to assess the performance aspect of the study. A three-versus-three game was played in the gymnasium on a wood floor surface. The playing area was a 40 -yard by 30 -yard grid with boundaries marked off by cones and lines on the floor. Players' shirt numbers were randomly chosen to select the two playing groups for each expertise level. Each team wore a different color shirt and all participants had a different number (the number was silk-screened on the front and back for clear identification). The ball was a "GrabBall" from the Sportime equipment catalog, which is made of a soft plastic material, spherical in shape but not solid, designed to enhance the skill of catching. The session was videotaped, keeping all players in view for the entire game. The camera-person was positioned on the top of a scaffolding 15 feet high and just off the playing area.

One team (defensive) started on one end-line and threw the ball to the opponents (offensive) standing on the opposite end-line. The offensive team tried to score by throwing the ball to a teammate (underhand throws), who had to catch it over the opposite team's end-line. After a score, the offensive team threw off to the opponents after both teams returned to their end-line. Players could not run with or dribble the ball; they had to maintain a pivot-foot or they lost possession of the ball. Defenders were restricted to play an arm's length away from their opponent and could only intercept the ball once it left the offensive player's hand. If the ball landed out of bounds, the team who did not throw it got possession and had to throw the ball in from the sideline. When the ball was dropped in the field of play, a change of possession at 
the spot where the ball fell would occur. Offensive players with the ball were limited to 10 seconds; the defender who played the ball carrier initiated the stall count. If the ball did not leave the offensive player's hands within 10 seconds there was a change of possession at the spot of the infraction. Two referees, with extensive experience in playing and teaching keep-away games; officiated the game.

Participants took part in warm-up activities (cardiovascular endurance and stretching) and an introductory offense-versus-defense activity (two versus one) to become familiarized with the game movement (and get used to being videotaped) prior to starting the directional keep-away game. Verbal and written directions were given to the participants; then they practiced the game for a few minutes, followed by a chance to ask final questions. The keep away-game directions are as follows:

"The gray team (defense) will start on one end-line and throw the ball to the maroon (offense) team who is standing on the opposite end-line. The offensive team tries to score by throwing the ball in an underhand motion to a teammate who must catch it over the opposite team's end-line. After a score, the scoring team throws off to the opponents after both teams return to their end-line. Players may not run with or dribble the ball, they must maintain a pivot foot or they will lose possession."

"Defenders must play an arm's length away from their opponent and can only intercept the ball once it leaves the offensive player's hand. If the ball lands out of bounds, the team who did not throw it gets possession and must throw the ball in from the sideline. A change of possession at the spot where the ball fell will occur if the ball lands on the floor. Offensive players with the ball will be limited to 10 seconds; the defender playing the ball carrier initiates the stall count by repeating 1 Mississippi... 10 Mississippi. If the ball does not leave the offensive player's hands before 10 seconds there is a change of possession on the spot of the infraction." 
Two games of three-versus-three will be played by each expertise group.

Two experts in the field (23 years and 36 years of experience in teaching physical education and coaching team sports), who have been trained using the Game Performance Assessment Instrument (GPAI), scored each player's off the ball movement during the game, using the GPAI scoring rubric. The observers watched the videotape and independently scored one performer at a time. 
Results

Inter-observer reliability was determined for the two expert coders who scored the GPAI and TKI. The coders scored each instrument independently. For any discrepancy in scoring, the two coders viewed the videotapes together to come to consensus and assign a final score. Some differences in score seemed to be due to interpretation, as most of the discrepancies in score were contained within the same component category. The researcher noticed this pattern in scoring with some of the GPAI components. The two expert coders discussed their interpretation of each component and came to agreement on a common meaning. They then came to consensus for all two point differences in scoring.

For any score that had a one point difference, the researcher viewed the videotape of both the GPAI and TKI (transcribing the participants' responses) and scored the performance or tactical scenario as a mediator to alleviate the discrepancy and determine a final score. To determine the final score for each participant, the researcher listed the components that had a one point difference, then viewed the videotape (concentrating on the listed components only), assigned a score, then compared her score with the scores of the original coders. The researcher's score always matched one of the coder's scores; therefore, this common score became the final score.

The two different procedures were used to account for the two separate reasons for the difference in scoring. The researcher was concerned that the original coders review the two point discrepancies together to be sure that there was consistency in their interpretation to be sure the components' scores were valid. The one point 
differences did not show the same pattern to suggest interpretation issues; therefore, the third party score was used to assign a final score. The researcher referred to the transcribed notes taken from the videotaped TKI responses, in addition to watching the videotape, to confirm actual responses, which added to the accuracy in scoring.

Quantitative statistics were then used to test the hypotheses: 1.to determine if there was a relationship between tactical knowledge and tactical performance; 2 . to determine if there was a difference in tactical performance among expertise groups; 3. to determine if there was a difference in tactical knowledge among expertise groups. All statistics were two-tailed and tested at an alpha-level of .05.

\section{Inter-Observer Reliability}

Results indicate a linear relationship between the two expert coders for the GPAI. Pearson $r$ statistics indicate a significant relationship, $r(32)=.95470, p<.0001$ for the overall GPAI scores of the two experts of this study. When the components were analyzed separately, a strong linear relationship was observed for: adjust - comes to meet the pass, $r(32)=.87001, p<.0001$; decision making - open space scores, $r(32)$ $=.82163, p<.0001 ;$ adjust - moves into space after a pass, $r(32)=.80848, p<.0001$; and support - forward movement into appropriate space, $r(32)=.80127, p<.0001$. A moderate linear relationship was observed for: decision making - synchronized movement, $r(32)=.75630, p<.0001$; support - back or lateral option, $r(32)=.76145$, $p<.0001$; and adjust - eludes opponent before cutting, $r(32)=.69422, p<.0001$.

Statistical analysis also revealed a linear relationship between the overall TKI rubrics score for the two experts coding the tactical game board scenario. There was a significant inter-observer reliability between coder's scores, $r(32)=.90098, p<$ 
.0001. All four components scored by the experts on the TKI showed moderate to strong inter-observer reliability: Verbal Solution, $r(32)=.75333, p<.0001$;

Offense/Defense Interplay, $r(32)=.77343, p<.0008$; Reason for Solution $r(32)=$ $.87598, p<.0001$; and Manipulate Solution, $r(32)=1.0000, p<.0001$. Differences in Overall GPAI and TKI Component Scores

Descriptive statistics for all 34 participants in this study are reported in Table 1. The total GPAI and TKI scores as well as the sub-scores representing components of each instrument show that some components have higher mean scores than others. The two components with the lowest means were: DMB - Decision Making by creating space for or moving into space vacated by another teammate $(M=2.20)$; and $\mathrm{AB}-$ Adjust by first eluding the defender to get into open space $(M=1.88)$. No study participant had a maximum score on these components, which represent higher level off-the-ball tactics that one would expect only high-level players to access. Correlated $t$-test analyses were completed to determine if one component mean was significantly different when compared to another components' mean on the GPAI. Table 1 summarizes the results of the Correlated $t$-tests for the study sample; vertical lines connect the components that were not significantly different. The most consistent and compelling differences in mean scores also involved the $\mathrm{DMB}$ and $\mathrm{AB}$ components. 
Table 1

Sample $(n=34)$ Mean Scores and Correlated t-tests

\begin{tabular}{|c|c|c|c|c|}
\hline Component & $M$ & $S D$ & Minimum & Maximum \\
\hline GPAI & $22.18(.634)$ & 4.56 & 11 & 31 \\
\hline DMA & $3.76(.752)$ & .60 & 2 & 5 \\
\hline SB & $3.76(.752)$ & .82 & 2 & 5 \\
\hline SA & $3.59(.718)$ & .74 & 2 & 5 \\
\hline $\mathrm{AC}$ & $3.56(.712)$ & .75 & 2 & 5 \\
\hline AA & $3.41(.682)$ & .96 & 1 & 5 \\
\hline I $\mathrm{AB}$ & $2.20(.440)$ & .81 & 1 & 4 \\
\hline I DMB & $1.88(.376)$ & .73 & 1 & 3 \\
\hline TKI & $6.26(.522)$ & 2.25 & 2 & 11 \\
\hline OD & $1.76(.587)$ & .70 & 1 & 3 \\
\hline $\mathrm{RS}$ & $1.74(.580)$ & .66 & 0 & 3 \\
\hline MS & $1.59(.530)$ & .70 & 1 & 3 \\
\hline | VS & $1.18(.393)$ & .83 & 0 & 3 \\
\hline
\end{tabular}

Note. Values enclosed in parentheses represent mean's proportion of the maximum possible score.

Maximum score Total GPAI $=35$ and each component $=5 ;$ Maximum score Total TKI $=12$ and each component $=3$. Components connected by vertical lines did not differ significantly at the .05 level using the Correlated $t$-test. GPAI $=$ Game Performance Assessment Instrument; TKI $=$ Tactical Knowledge Instrument; DMA = decision-making; moves to open space; DMB = decision-making; synchronized movement with teammates; $\mathrm{SA}=$ support - back; $\mathrm{SB}=$ support - forward; $\mathrm{AA}=$ adjust position - pass and move; $\mathrm{AB}=$ adjust position - elude opponent first $\mathrm{AC}=$ adjust position - come to meet ball; VS = verbal solution; $\mathrm{MS}=$ manipulate solution; $\mathrm{OD}=$ offense/defense interplay; $\mathrm{RS}=$ reasons for solutions. 
Significant differences were present when DMB was compared to all other GPAI components. There were strong differences in mean scores for DMA $\left(M_{d i f f}=1.88 ; s_{d i f f}\right.$ $=.54)$, correlated $t(33)=20.43, p<.0001 ; \mathrm{SA}\left(M_{\text {diff }}=1.71 ; s_{\text {diff }}=.63\right)$, correlated $t(33)=15.81, p<.0001 ; \mathrm{SB}\left(M_{\text {diff }}=1.88 ; s_{\text {diff }}=.59\right)$, correlated $t(33)=18.57, p<$ $.0001 ; \mathrm{AA}\left(M_{\text {diff }}=1.53 ; s_{\text {diff }}=.75\right)$, correlated $t(33)=11.92, p<.0001 ; \mathrm{AC}\left(M_{\text {diff }}=\right.$ $\left.1.68 ; s_{\text {diff }}=.64\right)$, correlated $t(33)=15.32, p<.0001 ;$ and a moderate difference for $\mathrm{AB}$ $\left(M_{\text {diff }}=.32 ; s_{\text {diff }}=.77\right)$, correlated $t(33)=2.46, p=.0194$.

In addition to the moderate difference in mean scores with $\mathrm{DMB}$, the $\mathrm{AB}$ component had strong differences in mean scores for DMA $\left(M_{\text {diff }}=1.56 ; s_{\text {diff }}=.56\right)$, correlated $t(33)=16.20, p<.0001 ; \mathrm{SA}\left(M_{\text {diff }}=1.38 ; s_{\text {diff }}=.65\right)$, correlated $t(33)=$ $12.36, p<.0001 ; \mathrm{SB}\left(M_{\text {diff }}=1.56 ; s_{\text {diff }}=.78\right)$, correlated $t(33)=11.57, p<.0001$; $\mathrm{AA}\left(M_{\text {diff }}=1.20 ; s_{\text {diff }}=.64\right)$, correlated $t(33)=10.97, p<.0001 ;$ and $\mathrm{AC}\left(M_{\text {diff }}=\right.$ $\left.1.35 ; s_{\text {diff }}=.69\right)$, correlated $t(33)=11.41, p<.0001$.

For the TKI, the VS component - participant's description of what needs to be done by the offensive team to solve the game situation $(M=1.18)$ was the lowest mean score. Many participants either neglected to respond or gave a very vague response to the initial question of what does their team have to do to keep possession of the ball.

Correlated $t$-test analyses were completed to determine if a TKI component mean was significantly different when compared to another TKI component. For the overall study sample, there were strong differences between the VS sub-score and OD $\left(M_{\text {diff }}=\right.$ $\left..59 ; s_{\text {diff }}=.89\right)$, correlated $t(33)=3.85, p=.0005 ;$ as well as RS $\left(M_{\text {diff }}=.59 ; s_{\text {diff }}=\right.$ $.86)$, correlated $t(33)=3.79, p=.0006$; the MS $\left(M_{\text {diff }}=.41 ; s_{\text {diff }}=.74\right)$, correlated $t(33)=3.23, p=.0028$ component had a moderate difference in mean scores. 


\section{Relationship Between GPAI and TKI}

The scatterplot of the 34 participants' total GPAI scores against their total TKI scores showed no compelling evidence of curvilinearity. The plot indicated a positive relationship between the two variables, however, they were not significantly correlated $r(32)=.271, p=.122$. This indicates that an increasing off-the-ball tactical knowledge score does not necessarily predict an increasing off-the-ball tactical performance score. Figure 1 compares the proportional mean scores for all components of both instruments. The components with the lowest proportional mean score for the study sample and each expertise group were almost identical. These results suggest that high level tactical movement as well as interpreting environmental stimuli (tactical knowledge) seemed to give participants the most difficulty.

Participants' GPAI and TKI scores were then analyzed by expertise group (Novice, Intermediate, and Expert) to determine if any of the expertise groups had a significant relationship between total GPAI and total TKI scores. There was not a significant correlation between scores for Novice participants, $r(9)=.260, p=.441$; Intermediate participants, $r(9)=.194, p=.568$; or Expert participants, $r(10)=.042, p$ $=.896$.

\section{Expertise Level Impact on Tactical Knowledge and Performance}

On all 13 variables (total GPAI, total TKI, 7 GPAI components, and 4 TKI components) the mean scores did progressively increase from Novice to Expert. However, contrary to prediction, these increases were significant in only four of 13 analyses (all involving the total TKI and two of its four components). This indicates that differences in the performance of off-the-ball tactics during game play were not 
Figure 1.

Lowest Proportional Scores

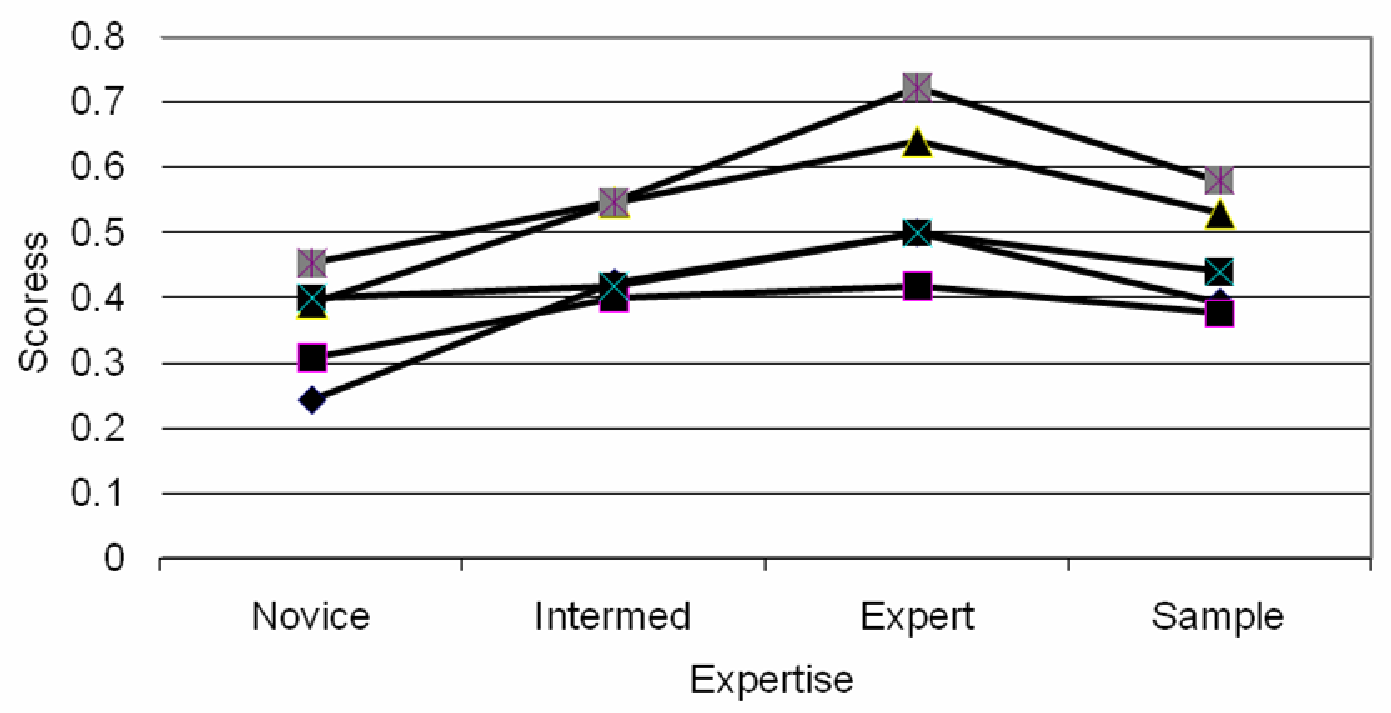

\section{$\rightarrow$ VS $\rightarrow-\mathrm{DMB} \rightarrow$ MS $\rightarrow$-AB $\rightarrow$ - RS}

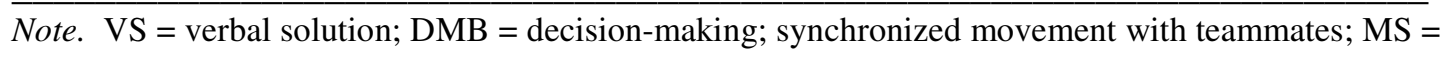
manipulate solution; $\mathrm{AB}=$ adjust position - elude opponent first; $\mathrm{RS}=$ reasons for solutions .

exceptionally apparent for varying levels of expertise. In fact, on no variable did all three groups differ significantly from each other. The between-group variability was insignificant because of the large within-group variability.

When determining if different levels of expertise have progressively higher mean scores for off-the-ball knowledge, as predicted, the total TKI scores differed significantly for the 11 Novice participants $(M=4.73)$, the 11 Intermediate participants $(M=6.36)$ and the 12 Expert participants $(M=7.58) ; F(2,31)=6.09, p=$ .0059. Pairwise multiple comparisons (using the Student-Newman-Keuls procedure at the .05 level of significance) found the Expert mean significantly higher than the 
Novice mean. The Intermediate mean did not differ significantly from either the Expert mean or Novice mean. This indicates that the tactical knowledge responses for Expert participants were far better in depth and breadth than the Novice group, but were not distinctive from the Intermediate group. The responses from the Novice and Intermediate groups were not significantly different.

The ANOVA procedure also was applied to the individual TKI components. The RS scores differed significantly for the 11 Novice participants $(M=1.36)$, the Intermediate participants $(M=1.64)$, and 12 Expert participants $(M=2.17) ; F(2,31)=$ $5.56, p=.0086$. Pairwise multiple comparisons (using the Student-Newman-Keuls procedure at the .05 level of significance) found the Expert mean higher than the Novice mean and Intermediate mean. This indicates the reasons given for the suggested tactical solutions the Experts gave were more often valid and more detailed than both the Intermediate and Novice groups.

The MS scores differed significantly for the 11 Novice participants $(M=1.18)$, the Intermediate participants $(M=1.64)$, and 12 Expert participants $(M=1.92) ; F(2,31)=$ 3.71, $p=.0359$. Pairwise multiple comparisons (using the Student-Newman-Keuls procedure at the .05 level of significance) found the Expert mean higher than the Novice mean. The Intermediate mean did not differ significantly from either the Expert mean or Novice mean. This indicates that the depth and breadth of suggested solutions the Experts gave to the tactical situation were significantly more elaborate than the Novice responses. The Intermediate mean did not differ significantly from either the Expert mean or Novice mean. Suggested solutions were not consistently 
inferior to those given by the Expert group or consistently superior to the solutions given by the Novice group.

The VS scores differed at a trend level of significance for the 11 Novice participants $(M=.73)$, the 11 Intermediate participants $(M=1.27)$, and 12 Expert participants $(M=1.50) ; F(2,31)=2.86, p=.0722$. This indicates that the participants' responses to "what needs to be done by the offensive team to solve the game situation" were only minimally different between expertise groups.

Correlated $t$-tests were completed after separating participants by expertise group. Table 2 (Novice), Table 3 (Intermediate), and Table 4 (Expert) summarize the differences in mean scores between components of the GPAI and TKI. Similar results were seen for every expertise level. The DMB and $\mathrm{AB}$ components had the most consistent and compelling differences in component mean scores.

The most significant differences in component scores for the Novice group were present when DMB was compared to all other GPAI components. There were strong differences in mean scores for DMA $\left(M_{\text {diff }}=2.09 ; s_{\text {diff }}=.30\right)$, correlated $t(10)=23.00$, $p<.0001 ; \mathrm{SA}\left(M_{\text {diff }}=1.82 ; s_{\text {diff }}=.60\right)$, correlated $t(10)=10.00, p<.0001 ; \mathrm{SB}\left(M_{\text {diff }}\right.$ $\left.=2.09 ; s_{\text {diff }}=.30\right)$, correlated $t(10)=23.00, p<.0001 ; \mathrm{AA}\left(M_{\text {diff }}=1.54 ; s_{\text {diff }}=.69\right)$, correlated $t(10)=7.45, p<.0001 ; \mathrm{AC}\left(M_{\text {diff }}=1.64 ; s_{\text {diff }}=.50\right)$, correlated $t(10)=$ $10.76, p<.0001$; and a moderate difference for $\mathrm{AB}\left(M_{\text {diff }}=.54 ; s_{\text {diff }}=.69\right)$, correlated $t(10)=2.63, p=.0251$. 
Table 2

Novice $(n=11)$ Mean Scores and Correlated t-test for the GPAI and TKI

\begin{tabular}{lllcc} 
Component & $M$ & $S D$ & Minimum & Maximum \\
\hline GPAI & $20.54(.587)$ & 4.37 & 15 & 27 \\
\multicolumn{1}{l}{ DMA } & $3.64(.728)$ & .67 & 3 & 5 \\
SB & $3.64(.728)$ & .81 & 3 & 5 \\
SA & $3.36(.672)$ & .50 & 3 & 4 \\
AA & $3.09(.618)$ & .70 & 2 & 4 \\
AC & $3.18(.636)$ & .87 & 2 & 4 \\
AB & $2.00(.400)$ & .94 & 1 & 4 \\
I DMB & $1.54(.308)$ & .69 & 1 & 3 \\
TKI & $4.73(.394)$ & 1.56 & 2 & 7 \\
OD & $1.45(.483)$ & .52 & 1 & 2 \\
RS & $1.36(.453)$ & .67 & 0 & 2 \\
MS & $1.18(.393)$ & .40 & 1 & 2 \\
I VS & $.73(.243)$ & .47 & 0 & 1 \\
& & & & \\
\hline
\end{tabular}

Note. Values enclosed in parentheses represent mean's proportion of the maximum possible score.

Maximum score Total GPAI $=35$ and each component $=5 ;$ Maximum score Total TKI $=12$ and each component $=3$. Components connected by vertical lines did not differ significantly at the .05 level using the Correlated $t$-test. GPAI $=$ Game Performance Assessment Instrument; TKI $=$ Tactical Knowledge Instrument; DMA = decision-making; moves to open space; $\mathrm{DMB}=$ decision-making; synchronized movement with teammates; SA = support - back; SB = support - forward; AA = adjust position - pass and move; $\mathrm{AB}=$ adjust position - elude opponent first; $\mathrm{AC}=$ adjust position - come to meet ball; VS = verbal solution; $\mathrm{MS}=$ manipulate solution; $\mathrm{OD}=$ offense/defense interplay; $\mathrm{RS}=$ reasons for solutions. 
Table 3

Intermediate $(n=11)$ Mean Scores and Correlated t-test for the GPAI and TKI

\begin{tabular}{|c|c|c|c|c|}
\hline Component & $M$ & $S D$ & Minimum & Maximum \\
\hline GPAI & $21.91(.626)$ & 5.47 & 11 & 27 \\
\hline SB & $3.84(.768)$ & .98 & 2 & 5 \\
\hline $\mathrm{AC}$ & $3.64(.728)$ & .67 & 2 & 4 \\
\hline DMA & $3.64(.728)$ & .67 & 2 & 4 \\
\hline SA & $3.45(.690)$ & .93 & 2 & 5 \\
\hline AA & $3.27(.654)$ & 1.27 & 1 & 4 \\
\hline $\mathrm{AB}$ & $2.09(.418)$ & .77 & 1 & 3 \\
\hline DMB & $2.00(.400)$ & .83 & 1 & 3 \\
\hline TKI & $6.36(.530)$ & 2.11 & 4 & 10 \\
\hline OD & $1.82(.607)$ & .60 & 1 & 3 \\
\hline MS & $1.64(.547)$ & .67 & 1 & 3 \\
\hline $\mathrm{RS}$ & $1.64(.547)$ & .50 & 1 & 2 \\
\hline VS & $1.27(.423)$ & 1.00 & 0 & 3 \\
\hline
\end{tabular}

Note. Values enclosed in parentheses represent mean's proportion of the maximum possible score.

Maximum score Total GPAI $=35$ and each component $=5$; Maximum score Total TKI $=12$ and each component $=3$. Components connected by vertical lines did not differ significantly at the .05 level using the Correlated $t$-test. GPAI $=$ Game Performance Assessment Instrument; TKI $=$ Tactical Knowledge Instrument; DMA = decision-making; moves to open space; DMB = decision-making; synchronized movement with teammates; $\mathrm{SA}=$ support - back; $\mathrm{SB}=$ support - forward; $\mathrm{AA}=$ adjust position - pass and move; $\mathrm{AB}=$ adjust position - elude opponent first; $\mathrm{AC}=$ adjust position - come to meet ball; VS = verbal solution; $\mathrm{MS}$ = manipulate solution; $\mathrm{OD}=$ offense/defense interplay; $\mathrm{RS}=$ reasons for solutions. 
Table 4

Expert $(n=12)$ Mean Scores and Correlated t-test for the GPAI and TKI

\begin{tabular}{|c|c|c|c|c|}
\hline Component & $M$ & $S D$ & Minimum & Maximum \\
\hline GPAI & $23.92(.683)$ & 3.42 & 19 & 31 \\
\hline DMA & $4.00(.800)$ & .43 & 3 & 5 \\
\hline SA & $3.92(.784)$ & .67 & 3 & 5 \\
\hline AA & $3.83(.766)$ & .72 & 3 & 5 \\
\hline $\mathrm{AC}$ & $3.83(.766)$ & .58 & 3 & 5 \\
\hline SB & $3.83(.766)$ & .72 & 3 & 5 \\
\hline I AB & $2.50(.500)$ & .67 & 2 & 4 \\
\hline |DMB & $2.09(.418)$ & .60 & 1 & 3 \\
\hline TKI & $7.58(.632)$ & 2.15 & 5 & 11 \\
\hline RS & $2.17(.723)$ & .58 & 1 & 3 \\
\hline OD & $2.00(.667)$ & .85 & 1 & 3 \\
\hline MS & $1.92(.640)$ & .79 & 1 & 3 \\
\hline VS & $1.50(.500)$ & .80 & 1 & 3 \\
\hline
\end{tabular}

Note. Values enclosed in parentheses represent mean's proportion of the maximum possible score.

Maximum score Total GPAI $=35$ and each component $=5$; Maximum score Total TKI $=12$ and each component $=3$. Components connected by vertical lines did not differ significantly at the .05 level using the Correlated $t$-test. GPAI $=$ Game Performance Assessment Instrument; TKI $=$ Tactical Knowledge Instrument; DMA = decision-making; moves to open space; DMB = decision-making; synchronized movement with teammates; $\mathrm{SA}=$ support - back; $\mathrm{SB}=$ support - forward; $\mathrm{AA}=$ adjust position - pass and move $\mathrm{AB}=$ adjust position - elude opponent first; $\mathrm{AC}=$ adjust position - come to meet ball; VS = verbal solution; $\mathrm{MS}$ = manipulate solution; $\mathrm{OD}=$ offense/defense interplay; $\mathrm{RS}=$ reasons for solutions. 
The AB component had strong differences in mean scores for DMA $\left(M_{d i f f}=1.54\right.$; $\left.s_{\text {diff }}=.69\right)$, correlated $t(10)=7.45, p<.0001 ; \mathrm{SA}\left(M_{\text {diff }}=1.27 ; s_{\text {diff }}=.79\right)$, correlated $t(10)=5.37, p=.0003 ; \mathrm{SB}\left(M_{\text {diff }}=1.54 ; s_{\text {diff }}=.82\right)$, correlated $t(10)=6.25, p<$ $.0001 ; \mathrm{AA}\left(M_{\text {diff }}=1.00 ; s_{\text {diff }}=.63\right)$, correlated $t(10)=5.24, p=.0004 ;$ and $\mathrm{AC}\left(M_{\text {diff }}\right.$ $\left.=1.09 ; s_{\text {diff }}=.70\right)$, correlated $t(10)=5.16, p=.0004$. The most significant differences in component scores for the TKI were present when the VS component was compared to all other TKI components. There were strong differences in mean scores for OD $\left(M_{\text {diff }}=.73 ; s_{\text {diff }}=.47\right)$, correlated $t(10)=5.16, p=.0004$ and $\mathrm{RS}\left(M_{\text {diff }}=.64 ; s_{\text {diff }}=\right.$ $.50)$, correlated $t(10)=4.18, p=.0019$ as well as a moderate difference in mean scores for MS $\left(M_{\text {diff }}=.45 ; s_{\text {diff }}=.52\right)$, correlated $t(10)=2.89, p=.0162$.

The most significant differences in component scores for the Intermediate group were present when DMB was compared to all other GPAI components. There were strong differences in mean scores for DMA $\left(M_{\text {diff }}=1.54 ; s_{\text {diff }}=.52\right)$, correlated $t(10)$ $=9.81, p<.0001 ; \mathrm{SA}\left(M_{\text {diff }}=1.36 ; s_{\text {diff }}=.50\right)$, correlated $t(10)=8.96, p<.0001 ; \mathrm{SB}$ $\left(M_{\text {diff }}=1.73 ; s_{\text {diff }}=.79\right)$, correlated $t(10)=7.29, p<.0001 ; \mathrm{AC}\left(M_{\text {diff }}=1.54 ; s_{\text {diff }}=\right.$ .69), correlated $t(10)=7.45, p<.0001 ;$ and a moderate difference for $\mathrm{AA}\left(M_{\text {diff }}=\right.$ $\left.1.18 ; s_{\text {diff }}=.75\right)$, correlated $t(10)=5.22, p=.0004$.

The $\mathrm{AB}$ component had strong differences in mean scores for DMA $\left(M_{d i f f}=1.64\right.$; $\left.s_{\text {diff }}=.50\right)$, correlated $t(10)=10.76, p<.0001 ; \mathrm{SA}\left(M_{\text {diff }}=1.45 ; s_{\text {diff }}=.69\right)$, correlated $t(10)=7.02, p<.0001 ; \mathrm{SB}\left(M_{\text {diff }}=1.82 ; s_{\text {diff }}=.75\right)$, correlated $t(10)=8.03, p<$ $.0001 ; \mathrm{AA}\left(M_{\text {diff }}=1.27 ; s_{\text {diff }}=.79\right)$, correlated $t(10)=5.37, p=.0003$; and $\mathrm{AC}\left(M_{\text {diff }}\right.$ $\left.=1.64 ; s_{\text {diff }}=.67\right)$, correlated $t(10)=8.05, p<.0001$. 
The most significant differences in component scores for the Expert group were present when DMB was compared to all other GPAI components. There were strong differences in mean scores for DMA $\left(M_{\text {diff }}=2.00 ; s_{\text {diff }}=.60\right)$, correlated $t(11)=$ $11.49, p<.0001 ; \mathrm{SA}\left(M_{\text {diff }}=1.92 ; s_{\text {diff }}=.67\right)$, correlated $t(11)=9.93, p<.0001 ; \mathrm{SB}$ $\left(M_{\text {diff }}=1.83 ; s_{\text {diff }}=.58\right)$, correlated $t(11)=11.00, p<.0001 ; \mathrm{AA}\left(M_{\text {diff }}=1.83 ; s_{\text {diff }}=\right.$ $.72)$, correlated $t(11)=8.85, p<.0001 ; \mathrm{AC}\left(M_{\text {diff }}=1.83 ; s_{\text {diff }}=.72\right)$, correlated $t(11)$ $=8.85, p<.0001 ;$ and a moderate difference for $\mathrm{AB}\left(M_{\text {diff }}=.50 ; s_{\text {diff }}=.80\right)$, correlated $t(11)=2.17, p=.0527$.

The AB component had strong differences in mean scores for DMA $\left(M_{\text {diff }}=1.50\right.$; $\left.s_{\text {diff }}=.52\right)$, correlated $t(11)=9.95, p<.0001 ; \mathrm{SA}\left(M_{\text {diff }}=1.42 ; s_{\text {diff }}=.51\right)$, correlated $t(11)=9.53, p<.0001 ; \mathrm{SB}\left(M_{\text {diff }}=1.33 ; s_{\text {diff }}=.78\right)$, correlated $t(11)=5.93, p<$ $.0001 ;$ AA $\left(M_{\text {diff }}=1.33 ; s_{\text {diff }}=.49\right)$, correlated $t(11)=9.38, p<.0001 ;$ and AC $\left(M_{\text {diff }}\right.$ $\left.=1.33 ; s_{\text {diff }}=.65\right)$, correlated $t(11)=7.09, p<.0001$. The only significant difference in component mean scores for the TKI occurred when the VS component was compared to the RS component. There was a moderate difference in mean scores $\left(M_{\text {diff }}=.67 ; s_{\text {diff }}=1.07\right)$, correlated $t(11)=2.15, p=.0544$.

\section{Participant Responses for the TKI}

Participant responses to the tactical problem were transcribed to further analyze the breadth and depth of their tactical knowledge. Table 5 summarizes some of the common responses for the verbal solution (participants' response to: "what needs to be done by your team to solve this game situation?"); manipulate solutions (tactical suggestions to solve situation); and reasons for the solution (rationale for suggestion) for each of the expertise groups. The researcher identified the game pieces as $\mathrm{x}_{1}$ (ball 
carrier) and $\mathrm{x}_{2}, \mathrm{x}_{3}$ (off-the-ball teammates) to illustrate the specific movement

participants were describing.

Table 5

Sample of the Common Participant Responses to the TKI Components

\section{$\underline{\text { Verbal Solution }}$}

Novice

1. blue team ...um ....get by the offense

2. build up a good defense... find a strategy on how to keep the ball amongst each other without giving it away

3. pass and have a good defense in order to keep the ball

4. come up with a strategy to keep the ball from the other team

5. talk to each other before play starts to come up with a plan

6. they need to have a plan

7. I need to get my team in a position to receive the ball... to get it in the goal

Intermediate

1. talk about a strategy to keep the ball and away from the other team

2. they need to set up a strategy

3. keep the ball away; move to an open spot so the ball can be passed to you or you need to move away from the player who is defending you

4. team needs to keep moving.... come up with some tactics to block opponents

5. keep moving to open spots

6 . we need to move around

7. spread out, get away from the opponents, get open, try to get a pass

8. set picks, get open to receive a pass, dribble

\section{Expert}

1. make fast cuts and run to open space; player with the ball has to be aware of where teammates are cutting to

2. get away from their players, set screens to get open, move closer together to get the ball

3. move around and stay away from the players and get open to an open spot so they will be able to get ball passed to them if necessary

4. one of them has to break free from their opponent to get possession

5. offense has to move around to get away from the ball; set screens and picks; use fakes and stuff to get away from other players

6. these players (off-the-ball) need to cut away from the ball then cut back to the ball to get open and lose their players

7. keep away from other team... move around to avoid the defense. 


\section{$\underline{\text { Manipulate Solution }}$}

Novice

1. dribble around, go by the red team, move toward other blue players

2. this player moves up maybe pass to them; this player come forward push toward goal

3. pass to other player and get pass back; pass to third teammate.... just keep passing among team members

4. try to hold the ball as long as I can 9-10 seconds by dribbling and moving, at 10 seconds pass to the next person... hopefully they will keep it 10 seconds

5. $\mathrm{x}_{2}$ cuts out wide (showed a lead pass away from the defense) to keep away from red; any time blue can get rid of the ball, keep ahead of red to keep possession; dribble and pass - if they keep moving and know where each other are - as long as keep in front of red should be fine

6. move around court dribbling; changing positions

7. I need to see where my teammates are... my teammates need to be in receiving position

8. toss to each other back and forth; keep running around with it; keep opponents busy while person with ball is trying to pass it

Intermediate

1. I'm trying to think of basketball situations - I have basketball plays in my head, I don't know how to phrase it

2. my team could fake them out and make cuts; just keep making cuts and get open; fake defender out and get to open area; set picks

3. don't want them to hold the ball very long; dribble to an open spot; use different passes; fake ball to one person then pass to the other

4. $\mathrm{x}_{2}$ can cut in then out, $\mathrm{x}_{1}$ can pass then $\mathrm{x}_{2}$ dribbles while $\mathrm{x}_{3}$ makes same in and out cut; go in front of defense and $\mathrm{x}_{3}$ can go around (pick and roll); $\mathrm{x}_{2}$ can cut out or in, receive a pass away from defender using a lob pass

5. jab in and cut in then out to get a pass, $x_{2}$ and $x_{3}$ set screens for each other and get open off of that; fake with the ball to one person, pass to the other

6. maneuver around and get open

7. $\mathrm{x}_{1}$ dribbles for 5 seconds and $\mathrm{x}_{3}$ gets in front of the red to get a pass; go back to $\mathrm{x}_{1}$ or $\mathrm{x}_{2}$ without red coming into the path of the ball; dribble and pass, switch directions to psych out other guys - just pass back and forth

8. screen away using basketball tactics; $\mathrm{x}_{2}$ and $\mathrm{x}_{3}$ get pass from $\mathrm{x}_{1}$; run around and get pass while red chasing 


\section{Expert}

1. $x_{1}$ dribbles left and passes to $x_{2}$ (no repositioning of $x_{2}$ ), $x_{2}$ dribbles away as $\mathrm{x}_{3}$ cuts to middle for a pass, $\mathrm{x}_{1}$ cuts away to corner and $\mathrm{x}_{3}$ dribbles toward $\mathrm{x}_{1}$ who receives a pass, $\mathrm{x}_{2}$ cuts back for a pass from $\mathrm{x}_{1}$

2. $\mathrm{x}_{3}$ takes player down and v-cuts back to get a pass, $\mathrm{x}_{1}$ goes away from the ball $\mathrm{x}_{3}$ dribbles toward $\mathrm{x}_{1}$ (showed defense trying to double team $\mathrm{x}_{1}$ ), $\mathrm{x}_{1}$ gets in an open lane to get pass or $\mathrm{x}_{2}$ cuts up and have an open player here - two options at once, $\mathrm{x}_{3}$ picks $\mathrm{x}_{2}$ who runs to open space for a pass; do a little give and go to get the ball back - $\mathrm{x}_{3}$ comes up to give the ball to her then cuts to get a pass back

3. just run around cycling the ball between the three, pass and cut to new space

4. these players (off-the-ball) can switch and cut up to get open for a pass; $\mathrm{x}_{1}$ fake passes and watches for others

5. $\mathrm{x}_{1}$ dribbles up the middle $\mathrm{x}_{2}$ sets up a v-cut then a back cut to get a pass, $\mathrm{x}_{1}$ moves to the outside (when prompted by the research assistant if she had any other solutions the participant responded with "probably, I just can't think of any")

6. $x_{1}$ dribbles to space, $x_{3} v$-cuts and moves to open space to get pass, $x_{2}$ cuts up to $\mathrm{x}_{3}$ to set pick so $\mathrm{x}_{3}$ can dribble by, $\mathrm{x}_{1}$ cuts forward to open space to get the pass; set a pick, dribble by, have $\mathrm{x}_{2}$ cut over here for a pass and $\mathrm{x}_{3}$ over here so he has two options - can pass the ball either way, move $\mathrm{x}_{2}$ so he has a back pass, pass real quick and cut away; dribble around awhile; keep cutting in and out

\section{$\underline{\text { Reasons for Solutions }}$}

Novice ( 3 of 11 participants did not give reasons for their solutions)

1. so I have some assistance

2. to give me someone to pass to

3. so I can get away faster

4. so opponents won't know what's happening

5. catch other team off guard

6. to get the ball

Intermediate (3 of 11 participants did not give reasons for their solutions)

1. to get a pass

2. so to get open

3. so they won't get trapped

4. to help a teammate

5. so have a better chance of getting the ball

6. to come closer to the ball 


\section{Expert}

1. to get open for a pass

2. to screen

3. so $\mathrm{x}_{2}$ can dribble or pass

4. so he has two options

5. so he has a back pass

6. to get opponent off you

7. to get open between defenders

8. because when go back defense cannot get it

Note. All participants responded to the tactical situation unless indicated in parentheses.

\section{Participants' Movement Experiences}

Participants were asked to recall what they thought the major emphasis was in elementary and middle school/high school physical education classes as well as interscholastic/intercollegiate sport practice. The participants chose between: 1 . drills to work on skills then game play to emphasize the skills; 2. game followed by a drill, if the game play was flawed, then a game with the emphasis on tactics; 3. recreational game play with little to no instruction; 4. cannot remember or did not participate in team sports (for the interscholastic/intercollegiate sport practice question). Chisquared tests were performed to investigate the differences among participants' selfreported movement experiences.

Table 6 shows participant responses for elementary physical education classes, middle/high school classes, and team sport practice (interscholastic and intercollegiate). The participants reported similar emphasis for the elementary school lessons. The proportion of Expert participants $(n=12)$, Intermediate participants $(n=$ 11), and Novice participants $(n=11)$ did not differ significantly in their response to

Question 1 on the Participant Questionnaire, $\chi^{2}(6, \mathrm{~N}=34)=3.98, \mathrm{p}=.6793$. 
Table 6

Responses to Questionnaire - Lesson and Team Sport Emphasis

\begin{tabular}{|c|c|c|c|c|c|c|}
\hline Response & $\begin{array}{l}\text { Total } \\
\text { Sample } \\
(n=34)\end{array}$ & $\begin{array}{l}\text { Novice } \\
(n=11)\end{array}$ & $\begin{array}{l}\text { Intermediate } \\
\qquad(n=11)\end{array}$ & $\begin{array}{l}\text { Expert } \\
(n=12)\end{array}$ & $\chi^{2}$ & $p$ \\
\hline \multicolumn{7}{|c|}{ Elementary School Emphasis } \\
\hline & & & & & 3.98 & .6793 \\
\hline Drills & $\begin{array}{l}65 \% \\
(n=22)\end{array}$ & $\begin{array}{l}64 \% \\
(n=7)\end{array}$ & $\begin{array}{l}64 \% \\
(n=7)\end{array}$ & $\begin{array}{l}67 \% \\
(\mathrm{n}=8)\end{array}$ & & \\
\hline TGU & $\begin{array}{l}9 \% \\
(n=3)\end{array}$ & $\begin{array}{c}9 \% \\
(n=1)\end{array}$ & $\begin{array}{l}18 \% \\
(n=2)\end{array}$ & $\begin{array}{c}0 \% \\
(\mathrm{n}=0)\end{array}$ & & \\
\hline Recreation & $\begin{array}{l}17 \% \\
(n=6)\end{array}$ & $\begin{array}{r}18 \% \\
(n=2)\end{array}$ & $\begin{array}{l}18 \% \\
(n=2)\end{array}$ & $\begin{array}{c}17 \% \\
(n=2)\end{array}$ & & \\
\hline $\begin{array}{l}\text { Cannot } \\
\text { Recall }\end{array}$ & $\begin{array}{l}9 \% \\
(n=3)\end{array}$ & $\begin{array}{c}9 \% \\
(\mathrm{n}=1)\end{array}$ & $\begin{array}{l}0 \% \\
(n=0)\end{array}$ & $\begin{array}{l}16 \% \\
(n=2)\end{array}$ & & \\
\hline
\end{tabular}

High School/Middle School Emphasis

$7.75 \quad .2571$

\begin{tabular}{llccc} 
Drills & $\begin{array}{l}53 \% \\
(\mathrm{n}=18)\end{array}$ & $\begin{array}{l}46 \% \\
(\mathrm{n}=5)\end{array}$ & $\begin{array}{l}36 \% \\
(\mathrm{n}=4)\end{array}$ & $\begin{array}{l}75 \% \\
(\mathrm{n}=9)\end{array}$ \\
TGU & $\begin{array}{l}9 \% \\
(\mathrm{n}=3)\end{array}$ & $\begin{array}{c}18 \% \\
(\mathrm{n}=2)\end{array}$ & $\begin{array}{c}9 \% \\
(\mathrm{n}=1)\end{array}$ & $\begin{array}{c}0 \% \\
(\mathrm{n}=0)\end{array}$ \\
Recreation & $\begin{array}{l}35 \% \\
(\mathrm{n}=12)\end{array}$ & $\begin{array}{c}27 \% \\
(\mathrm{n}=3)\end{array}$ & $\begin{array}{l}55 \% \\
(\mathrm{n}=6)\end{array}$ & $\begin{array}{c}25 \% \\
(\mathrm{n}=3)\end{array}$ \\
Cannot & $\begin{array}{l}3 \% \\
\text { Recall }\end{array}$ & $\begin{array}{c}9 \% \\
(\mathrm{n}=1)\end{array}$ & $\begin{array}{c}0 \% \\
(\mathrm{n}=0)\end{array}$ & $\begin{array}{c}0 \% \\
(\mathrm{n}=0)\end{array}$ \\
\hline
\end{tabular}




\begin{tabular}{lcccccc}
\hline Response & Total & Novice & Intermediate & Expert & $\chi^{2} \quad p$ \\
& $\begin{array}{l}\text { Sample } \\
(n=34)\end{array}$ & $(n=11)$ & $(n=11)$ & $(n=12)$ & \\
\hline
\end{tabular}

Team Sport Emphasis

$25.66<.0001$

$\begin{array}{lcccc}\text { Drills } & \begin{array}{c}68 \% \\ (\mathrm{n}=23)\end{array} & \begin{array}{c}18 \% \\ (\mathrm{n}=2)\end{array} & \begin{array}{c}91 \% \\ (\mathrm{n}=10)\end{array} & \begin{array}{c}92 \% \\ (\mathrm{n}=11)\end{array} \\ \text { TGU } & \begin{array}{c}6 \% \\ (\mathrm{n}=2)\end{array} & \begin{array}{c}0 \% \\ (\mathrm{n}=0)\end{array} & \begin{array}{c}9 \% \\ (\mathrm{n}=1)\end{array} & \begin{array}{c}8 \% \\ (\mathrm{n}=1)\end{array} \\ \text { Recreation } & \begin{array}{l}0 \% \\ (\mathrm{n}=0)\end{array} & \begin{array}{c}0 \% \\ (\mathrm{n}=0)\end{array} & \begin{array}{c}0 \% \\ (\mathrm{n}=0)\end{array} & \begin{array}{c}0 \% \\ (\mathrm{n}=0)\end{array} \\ \begin{array}{l}\text { Did Not } \\ \text { Play }\end{array} & \begin{array}{l}26 \% \\ (\mathrm{n}=9)\end{array} & \begin{array}{c}82 \% \\ (\mathrm{n}=9)\end{array} & \begin{array}{c}0 \% \\ (\mathrm{n}=0)\end{array} & \begin{array}{c}0 \% \\ (\mathrm{n}=0)\end{array}\end{array}$

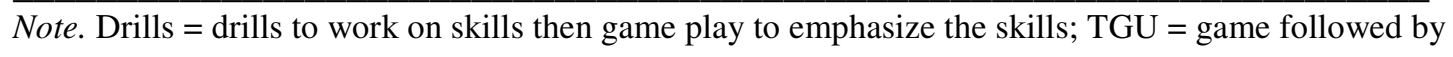
a drill, if the game play was flawed, then a game with the emphasis on tactics; Recreation = recreational game play with little to no instruction; Do not recall $=$ cannot remember; Did not Play $=\operatorname{did}$ not participate in team sports.

This self-reported data indicate two-thirds of the study participants recall drills to improve skills to be the most common emphasis in class.

Participant responses for middle school/high school physical education class emphasis also were similar. The proportion of Expert participants $(n=12)$, Intermediate participants $(n=11)$, and Novice $(n=11)$ did not differ significantly in their response to Question 2 on the Participant Questionnaire, $\chi^{2}(6, \mathrm{~N}=34)=7.75, p$ $=.2571$. 
Participant responses for reporting the interscholastic/intercollegiate sport practice emphasis differed by expertise group. The proportion of Expert participants $(\mathrm{n}=12)$, Intermediate participants $(n=11)$, and Novice $(n=11)$ did differ significantly in their response to Question 3 on the Participant Questionnaire, $\chi^{2}(4, \mathrm{~N}$ $=34)=25.66, \mathrm{p}<.0001$. When asked about what they thought the sport practice emphasis was, $68 \%$ of the participants $(n=34)$ recalled drills to work on skills then game play to emphasize the skills was the major emphasis. The Intermediate and Expert groups had similar responses to Question 3. The Intermediate participants $(91 \%)$ and Expert participants $(92 \%)$ recalled drills to practice skills were the main emphasis during practice. However the predominant response for the Novice participants $(82 \%)$ reported they did not play interscholastic or intercollegiate sport. This is what accounted for the significant difference in responses. 


\section{Discussion}

The results of this study only partially supported the original hypotheses. There was no evidence of a correlation between participants' GPAI and TKI scores, indicating no relationship between off-the-ball tactical knowledge and off-the-ball tactical performance. Furthermore, the game performance scores did not necessarily increase as participants' expertise level increased. The tactical knowledge scores did differ depending on level of expertise; however, there was only a significant difference between Novice participant and Expert participant scores.

Effective game play is a result of proper response selection and skill execution. It involves perceiving environmental cues to guide decision-making concerning the execution of appropriate off-the-ball movement or on-the-ball skills. Effective players know when and where to move in addition to how to move. Results of this study reveal that the off-the-ball movement and tactical knowledge necessary to be effective games players were not present for all participants. Even those who reported they had experiences in invasion/territorial games did not always possess the off-the-ball qualities of an effective games player.

The lack of significant differences in scores among expertise levels suggests that players, especially at the intermediate and expert level, may have better skills but do not necessarily have higher levels of game cognition. The scores should have been more clearly distinguishable for Expert and Intermediate players as well as between Intermediates and Novice players. Off-the-ball tactics did not seem to be a valid indicator of invasion/territorial game expertise for this study sample. These results provide evidence that current teaching methods may need to be investigated, which 
could lead educators and coaches toward a better way to develop more effective players.

The researcher does recognize that the sample size for this study was relatively small $(n=34)$. A larger sample size may have provided a greater opportunity to include participants at both extreme ends of the tactical knowledge and performance scoring spectrum. In addition, the original plan was to have 36 participants (12 in each expertise group) randomly drawn from those who agreed to participate. However, only $25 \%$ (45 of 180) of the prospective participants returned the questionnaire and agreed to participate, therefore everyone was scheduled to take part in the study. Of the 45 participants who returned questionnaires, $24 \%$ did not come on the data collection day due to injury, illness, or last minute commitments. This might have impacted the true random representation of participants; however, each participant did fit the expertise qualifications established by the researcher; and the sample did represent the appropriate levels of expertise to study the hypotheses. Also, this study controlled for gender and it cannot be assumed that scores for male participants would have had the same results.

\section{Tactical Knowledge and Tactical Performance}

One hypothesis for this study stated that players' tactical knowledge of off-the-ball movement in invasion/territorial games directly and positively parallel their tactical performance in invasion/territorial games. This was not the case; there was not a significant positive correlation between players' GPAI scores and their TKI scores. Intuitively, one would think if players had an advanced level of tactical performance they would also have a high level of tactical knowledge. This study controlled for 
skill by restricting the sport specific skills to underhand throwing, catching, and running, which are fundamental skills and usually mastered at an early age. This may have reduced the options available to participants especially when they had the ball. The nature of the game chosen for this study, could have limited the variability of movement choices. As an example, the underhand toss could have prohibited long passes down court to penetrate the defense, which would have been possible using an overhand throw. Also, restricting the ball carrier to passing without the option of running with the ball could have prohibited them from moving the defenders to open passing lanes to teammates.

Even though this study concentrated on off-the-ball movements, the players were still dependent on the teammate with the ball to be successful. Results of this study reflect those of Nevett, Rovegno, Babiarz, and McCaughtry (2001), which concluded that on-the-ball skills and off-the-ball movement cannot be separated and are inherently connected. Therefore, some off-the-ball options may not have been used by the participants due to the restrictions of the game (i.e., size of the court, number of players, and length of the game).

Participants in this study may have acted instinctively (tactical performance), but could not describe what they did and why they did it (tactical knowledge). Participants may have reacted to a situation but did not take into consideration the environmental cues produced by their teammates or opponents. They may not have incorporated other players' actions into their response selection decisions therefore, could not justify their decisions in relation to what else was happening in the game. 
Conversely, players may have known how to solve the tactical problem (tactical knowledge), but could not put their response selection into action in a timely or effective manner (tactical performance). These results provide evidence for the work of Grehaigne et al. (2001), which states that decisions are only valid if they are transformed into appropriate actions. These results also support the conclusions of Rink, French, and Tjeerdsma (1996). When players are involved in a highly dynamic, ever-changing invasion/territorial game, in which decisions must be made quickly and in context of the game, many players may not be able to incorporate appropriate decisions because of the pace of the game and the constantly changing interaction of teammates and opponents. Therefore teaching/coaching methods that provide experiences, which allow players to make decisions based on environmental cues, will lead to more appropriate game decisions and ultimately more effective players.

The scoring rubric for the GPAI had a scoring range of one to five points; however, none of the means for the components were above 3.76 for the entire sample and there was a three point range for all components except one. There was no evidence of one expertise group skewing these results because when each component mean was calculated by expertise group, no component mean was significantly different from the other expertise groups' mean scores. The scoring rubric for the TKI had a range of one to three points for each component. No component mean was higher than 1.76 for the entire sample, even though tactical knowledge means did differ significantly between the Novice and Expert groups, only the OD and RS mean scores were above two (2.00 and 2.17 respectively) points for the Expert group. The range of scores for 
the components on the TKI were two for the MS and OD components and three for the VS and RS components.

These low mean scores are due to large within-group variability and explain the insignificant between-group differences in off-the-ball performance and knowledge. These results suggest that even though the study's participants were classified as Expert (multiple interscholastic and/or intercollegiate experiences) or Intermediate (limited invasion/territorial interscholastic experience or intercollegiate non invasion/territorial experience) their GPAI and TKI scores did not follow a typical or expected pattern of both GPAI and TKI scores for Intermediates falling between and significantly different from the scores of the Novice and Expert groups.

The participants' scores were categorized by expertise group when the GPAI and TKI scores were compared. There was not a compelling pattern for having both scores increase or even decrease simultaneously. Many participants $(n=18)$ had one instrument score above the expertise group's mean score and the other instrument score below the expertise group's mean score. These results are contrary to the French and McPherson (2004) study that concluded both, knowledge and skill increase with experience.

For the Novice group, 6 of the 11 participants had mixed results (one instrument score increasing and the other instrument score decreasing). The category that represented the most Novice participants $(n=4)$ was GPAI score below their expertise mean and TKI score above the expertise mean. One would anticipate that novice players consistently would have low GPAI and TKI scores. These mixed results may be due to some Novice participants' having a lack of experience in playing 
invasion/territorial games but, may have watched others' play or could intuitively problem solve to offer basic tactical solutions better than other Novice participants. Another consideration could be that even though the Novice participants reported they did not play any interscholastic or intercollegiate sport, some may have had more instructional experiences in physical education or recreational endeavors that gave them an advantage over other Novices when completing the GPAI and TKI.

The Intermediate group had 7 of 11 participants with mixed results. A larger number of participants $(n=5)$ had GPAI scores above the Intermediate expertise mean and TKI scores below the mean. These results may be due to the intermediate group using their team sport experience to aid in their game play however, they were not able to articulate what they should do in a game situation and why they would do it. This lack of tactical knowledge is troublesome as players are not able to reach their optimal level without being able to analyze their options, which indicates, yet again, a need for an alternative vision/method for teaching and coaching.

The Expert group was the only group to have both scores increase and decrease simultaneously; 7 of the 12 participants had parallel results. The highest number of Expert participants $(n=4)$ had both GPAI and TKI scores above the expertise mean. The other three participants had both scores below the expertise mean. Intuitively, one could conclude that high level players, those who have multiple interscholastic and intercollegiate invasion/territorial game experiences, should have high tactical performance and tactical knowledge. However this scenario did not occur for most of the Expert group. Expert players may make instinctive off-the-ball movement decisions (moving without conscious thought) but, may not know why they make the 
choices. Or alternatively, they may have an advanced knowledge of what should be done but, they do not execute the appropriate off-the-ball movements in the game situation.

\section{Tactical Performance}

The hypothesis that participants' GPAI scores (indicating their off-the-ball movement in a game) would increase as their level of expertise increased was not supported in this study. The mean scores increased for the total GPAI score and every component - the Novice group had lowest mean scores, the Intermediate group scores were next and the Expert group always had the highest mean scores. However the differences in scores were not compellingly significant. These results agree with those of the Nevett, Rovegno, Babiarz, and McCaughtry (2001) aerial basketball study. After participating in a 12-lesson unit both the low-skilled and high-skilled groups improved their good cutting decision scores from pre- to posttest, however not to a significant level. Also the higher-skilled players' scores were always higher than the lower skilled players indicating they may have better perceptual and decision-making processing ability.

The DMB (decision-making: synchronized movement) and AB (adjust: elude opponent) mean scores were the lowest across all expertise groups. These mean scores were the only components that averaged below a three on the GPAI rubric. Correlated $t$-test results indicate that the DMB and AB scores were significantly different than the other GPAI component scores at every expertise level. One would assume that the Novice group, those with very little to no experience playing invasion/territorial games would score low on cutting to a space vacated by a 
teammate or creating space for a teammate to run into (DMB) and trying to elude an opponent prior to cutting (AB) because these are higher level tactics. More advanced players would be able and should be able to access these tactics for more effective game play. For this study, few players regardless of expertise group, regularly considered teammate movement to guide their off-the-ball decisions. As an example, during the keep-away game, the two off-the-ball players moved into the same space because neither player considered the other's movement. The other vital tactic necessary for becoming an option for the ball carrier is to lose an opponent who is playing "man-to-man" defense. A high level player should use a variety of fakes to get a space advantage on his or her defender, which allows them to be a viable option to pass to. However, very few participants used this tactic to rid themselves of their opponent.

The reasons for such low mean scores for the DMB and $\mathrm{AB}$ components, especially for the Intermediate and Expert groups, may be due to the participants continually doing what was familiar to them. Most players, when they did attempt to lose their opponent, limited their eluding tactics to a v-cut (taking two-to-three steps in one direction then pivot and cut sharply into open space in the opposite direction) while a few players set a screen for the other off-the-ball teammate (to run her defender into to become free). Even though there are an abundance of other options (e.g., backdoor, double cut, rub off, spin, screen and roll, spin, forward rocker step and fade back, Lcut, change of speed, shoulder fake) they were hardly ever tried by study participants. These options are regularly and appropriately used during invasion/territorial games. It was expected that the Intermediate and Expert groups would try some of these 
alternatives, especially those players who had extensive interscholastic and intercollegiate experience. However, the players continually used the same option or did not attempt to elude their opponent. This may be due to players being comfortable with a certain move, not being exposed to other alternatives, or never being introduced to the tactic. The uniqueness of the keep-away game or the unfamiliar teammates may have also contributed to the lack of variety with off-the-ball movement choices.

Another reason for the similarities in mean scores across expertise groups for tactical performance could be that on-the-ball skills are what separate a Novice from an Expert. The results of this study mirror the French et al. (1995) baseball study, which concluded that expertise was a factor for skills but, had little impact on game decisions. Participants' off-the-ball tactical decisions made during the keep-away game were not significantly different for those considered to be novices, intermediates, or experts. In addition, the skills used in this study's keep-away game, were fundamental skills and all participants used them proficiently so, little difference was seen; neutralizing participants' off-the-ball performance.

Limitations of the study may have caused the low mean scores for components of the GPAI, especially for the Intermediate and Expert groups. The criteria used to classify participants as novice, intermediate, or expert may need to be more clearly delineated. Perhaps setting higher criteria for the expert group such as collegiate Most Valuable Players (MVP) of invasion/territorial games or recruited Division I players would give a better indication of off-the-ball expertise. The homogeneous grouping of participants may have limited the off-the-ball options for the Intermediate group. Intermediates may have performed better if they were part of a heterogeneous group 
where Experts could have modeled off-the-ball movements. Defenders may not have been playing strong defense so there was no need to elude the defender so direct cuts to open space or the ball were just as effective. Opportunities to come back in support of the ball carrier or moving to a forward position at the appropriate angle may not have been available for a participant to choose because another teammate accessed that option first. Also, the participants did not have previous experience playing with their randomly chosen teammates. The anticipation of what a teammate will do in certain game situations was not possible and may have restricted effective synchronized movement with partners in the study.

\section{Tactical Knowledge}

The hypothesis that participants' TKI scores (indicating their off-the-ball tactical knowledge) would increase as their level of expertise increased was partially supported in this study. The Expert group's mean scores for the total TKI, RS (reason for solution), and MS (manipulate solution) were significantly different from the Novice group's mean scores. However, the Intermediate group's mean scores did not differ significantly from either the Novice or Expert groups for the total TKI, RS, or MS. There was a trend level difference in VS (verbal solution) scores for expertise groups, the Novice group had the lowest mean score followed by the Intermediate group then the Expert group; however, the difference was not statistically significant. The OD (offense/defense interplay) component mean scores did not differ significantly for each expertise group.

The difference in tactical knowledge of the Expert group versus the Novice group was clearly present when participants' were asked what needed to be done to solve the 
tactical situation on the TKI game board (VS). Many of the novice participants were very vague about their options. A common response was that the team would have to "come up with a plan," or "talk to each other before they play." These options are not tactics to consider during the game to be successful in keeping the ball for two minutes. Additionally, there were no suggestions concerning what that plan might include. Often, the Novice group confused the offense with the defense stating their team must "build a good defense;" "get by the offense;" or "pass and have a good defense." These convoluted responses also were reported in studies by French and McPherson, "many participants, especially beginners and novices, display great difficulty representing the problem. The novice or beginner may access much sportrelated knowledge; however, it is often not the relevant knowledge needed for successful performance of the specific sport task" (Weiss, 2004, p. 409).

The Expert group, on the other hand, was much more specific about what their team had to do to be successful. Most participants offered responses that included offthe-ball players must fake or "break free" from their opponent and cut to open space; "move around and stay away from the players;" and "cut away and come back to the ball." These responses clearly indicated an understanding of the situation and the Experts' ability to access previous experiences.

The Intermediate groups' responses fluctuated between those that were similar to the Novice group, such as the need to set up a strategy and "we need to move around or spread out," while some responses were more specific such as "get away from opponents," "get open," and "move to an open spot." The range of responses is what accounted for the lack of significant difference in the Intermediate groups' scores. It 
was not always apparent that the participants knew what to do or how to articulate their answers.

Similar results were reported in a study where students were asked to view a threeversus-three soccer game then describe what they saw on the videotape (Placek, Griffin, \& Dodds, 2001). Responses of experienced (played on organized teams) and inexperienced participants were categorized according to when accurate responses were given (prior to prompts, after open-ended generic prompts, or after direct prompts). The authors concluded, "while soccer experience seemed to help students identify bunching up immediately, the reverse case (less experienced players not identifying bunching up until the third question) was not compelling" (p. 33). They also reported that more than expected experienced as well as inexperienced players only recognized bunching up (tactical problem) after having a direct prompt.

The extent, to which the participants moved the game pieces and offered alternatives to solve the tactical problem (MS), also was significantly different between the Novice and Expert groups. The Novices' consistently described "global" or very general solutions such as "move around the court;" "keep running around with the ball;" and "keep opponents busy" however, they did not offer specific moves or continuous movement of all teammates. Some of the responses were not logical or realistic for the game situation. Participants suggested that the person with the ball hold on to it for 10 seconds then give it to the next person who holds on to it for 10 seconds, or "just toss it back and forth;" and "this player pushes toward the goal" (there was no goal in this keep-away game). 
The majority of the Expert group showed more explicit movement of the offensive players and offered specific movements as solutions. They showed much more offthe-ball movement to give the ball carrier different options. However, they too lacked movements that showed possible interactions between the two off-the-ball teammates. Concentration was always placed on one of the off-the-ball players trying to help the ball carrier. The Expert group often described continuous movement where the Novice group showed "set plays" then returned the pieces back to the original positions. The Expert group included dribbling, faking a pass, cutting to open space, setting picks, v-cut back for a pass as options for the offensive team and regularly showed these movements on the game board. Once again the past experiences of the Expert group seemed to make them more comfortable with moving the game pieces and describing alternatives to solve the tactical problem.

Some $(n=3)$ of the Novices did offer more specific options and more of the Intermediate group showed viable alternatives to solve the tactical problem as explicitly as the majority of the Expert group. However, it certainly was not demonstrated by all members of each expertise group. In fact, there were even a couple $(n=2)$ Experts who said, "just run around cycling the ball between the three." This gives credence to why there was not a significant difference between Novice and Intermediate or Intermediate and Expert MS scores. Moreover, while the Intermediates and Experts described more specific alternatives, most of them gave the same solution over and over (v-cuts or running to an open space). They were quick to stop once they described the same moves several times. Interestingly, this lack of 
variety also was depicted while playing the keep-away game and affected their tactical performance.

Also some of the participants stated that they knew what to do but "could not describe it" or "think of it right now." One Intermediate participant responded "I'm trying to think of basketball situations - I have basketball plays in my head, I don't know how to phrase it."

Only one or two participants, in the entire sample, showed ways to elude opponents prior to cutting to open space. Moves showing direct cuts with the opponent still playing tight defense or a total disregard for the defense were common. There are many options (e.g., head fake, shoulder fake, fake with the ball, backdoor cut, crossover dribble, give and go, screens, switching positions) available to "get rid of the opponent," but these were suspiciously omitted by a large majority of the sample. Very few of the participants $(n=2)$ moved the third game piece so the ball carrier would have a second option and no one moved the third game piece prior to the second piece receiving the ball from the ball carrier to indicate an understanding of off-the-ball movement beyond the immediate pass ("thinking two passes ahead").

While the quality of responses given by the Expert group were more impressive than the Novice group, it was surprising that the Intermediate group's responses could not be more clearly distinguishable from either the Expert or Novice group. The protocol of the study may have impeded the participants' responses. Some may have felt anxious about being in a novel situation. Participants may have been nervous or intimidated and they rushed through the situation. They may have been concerned that they were not giving the "correct answers" so they limited their response to what they 
were most comfortable with. Participants may not have wanted to risk a wrong response or look foolish in front of the research assistants. The researcher tried to make the data collection method as comfortable as possible and it was not apparent that any of the participants were overly apprehensive; however, this may have been an issue.

Placek et al. (2001) offered a compelling explanation of why more experienced participants in their tactical knowledge study did not "offer more sophisticated analyses of the problems caused by bunching up or better solutions to bunching up." Their conclusions have merit for this study "most often in physical education students are asked to do rather than to explain" (p. 37). Students, as well as team sport players, are not often asked to explain why a particular response was selected. Therefore, they may not be able to critically think of alternatives in a timely manner or clearly articulate the options to others because games players are not accustomed to thinking critically about physical activities.

Also the type of responses given could be explained by some participants having less experience in playing invasion/territorial games, which may have affected their understanding of the tactical problem and inhibited their ability to think of solutions. It could be because they have not played enough to recognize options from environmental cues, store the options in memory, and then be able to retrieve them when needed. This also could explain why some participants used invasion/territorial game terms but not in proper context. Another explanation may be that as players, they were not required to recognize the tactical problem and solve it on their own, but were explicitly told by teachers or coaches what to do and when to do it. 
The quantity of different alternatives suggested by participants also was intriguing. There was not much variety in the options offered, especially in the Intermediate and Expert groups, even though they have all played interscholastic and/or intercollegiate sport. It could have been that they were not exposed to all the different options available for common tactical problems, or that they were unable to recognize what the best options were for the tactical problem. Because of the pressure of the situation they may have relied on what they were comfortable with. Or, perhaps there was little emphasis on tactics during instruction or practice.

Participants also were asked to supply the reasons for the movements they suggested when solving the tactical situation (RS). There was only a trend level difference in responses between expertise groups. Several of the Novice and Intermediate participants did not give any reasons for why the option was selected, which indicates they may not have known why they chose a particular alternative. The Expert group regularly gave logical and more precise reasons for the suggested movements. However, very few participants, regardless of expertise level, incorporated the opponents into their reasons for movement. These results are contradictory of the conclusions presented by French and McPherson (Weiss, 2004). Interviews conducted after a tennis point indicated "adult experts were basing some actions on assessments of their opponent's weaknesses" (p. 418).

Off-the-ball movement is often executed to bring defenders away from the ball carrier, to take them out of an open space, to get a spatial advantage on them, or to help a teammate get free from his or her defender. "I am doing this so the defender 
will do that" was hardly ever articulated and is especially vital to be successful in invasion/territorial games.

When players do not have a legitimate rationale for why they move in games, the end product often becomes individual movement that does not coincide with teammates' or opponents' movement. The results include off-the-ball players running into the same space, or removing themselves as a viable option because they do not select the best option for the situation. Many players will move because they know they must move but, unless they know why they are moving they will not optimize their team's chance for success in a game.

In this study, participants may have had the capacity to focus on one move at a time, one offensive player at a time, this inhibited their ability to visualize the entire tactical problem and rationalize the movements of teammates and opponents to solve the problem. They may have never had the opportunity to look at a tactical problem beyond their own responsibilities. As an example, many players know what they should do in a set play or in a certain position; however, often they do not fully comprehend what their teammates' roles are or how to exploit their opponents. This may help to explain the similarity in responses across expertise groups.

\section{Responses to Participant Questionnaire}

The participants' responses to the questions concerning past experiences indicate a clear skill-based emphasis in physical education classes and team sport practice sessions. The self-reported responses have not been verified and are considered a limitation of the study. However, the questions were reviewed with the participants and the options were clearly explained. Over $60 \%$ of each expertise group reported 
the emphasis of their elementary physical education class experience was on drills, followed by a game to practice those skills. The participants' responses to middle/high school physical education class emphasis were split between two categories: drills to practice skills then a game to practice those skills or recreational play with little to no instruction. The Novice group reported $46 \%$ and $27 \%$ respectively; the Intermediate group reported $36 \%$ and $55 \%$ respectively; and the Expert group reported $75 \%$ and $25 \%$ respectively in response to the question.

The team sport practice emphasis was overwhelmingly skill-based as the Intermediate and Expert groups (91\% and 92\% respectively) reported that drills to practice skills and a game to practice those skills was what they recollected. The responses to each question demonstrate a clear emphasis on skill development through drills perhaps at the exclusion of opportunities to enhance tactical awareness concerning how to apply those skills or off-the-ball movements. This may provide evidence as to why there were no differences in tactical performance among expertise groups; why players' tactical knowledge did not correlate with their tactical performance; and why there was only a distinct difference in tactical knowledge between Expert and Novice groups but not Expert and Intermediate, or Intermediate and Novice groups.

\section{Study Implications}

The participants' GPAI and TKI scores along with their self-reported recollections of what was emphasized in physical education class and team sport practice corresponds with the conclusions of the Nevett, Rovegno, and Babiarz (2001) study. They conclude, "When instruction focuses solely on motor skill execution and lacks 
tactical knowledge instruction, the performers will not acquire the needed game strategies to be competent" (p. 401). Tactical knowledge scores and tactical performance scores were not exceptionally high for any expertise group. Because of the skill development emphasis, participants may not have been exposed to tactical concepts and how they are applied in game situations. French and McPherson believe "response selection processes are largely learned and do not improve without extensive practice that focuses explicitly on their development and improvement" (Weiss, 2004, p. 408).

Participants' responses to the Questionnaire may provide a rationale for the study's findings. Overwhelmingly, the participants recalled that the emphasis for physical education lessons and team sport practice was based on the development of skills. The cognitive aspect, which is important to developing effective games players, seemed to be excluded. Results of this study may be evidence that the skill-based method of teaching is not be the best way to help students/players progress in becoming effective invasion/territorial games players.

Traditional teaching methods (direct teaching style) for team sports, especially invasion/territorial games, continue to dominate the lesson and practice plans for instructors. These methods often neglect the knowledge component and focus entirely on the technique aspect. If knowledge is addressed it is rare that "conceptual" teaching is utilized. The reason teachers are so technique oriented is a result of the emphasis placed upon skill acquisition courses and upon measurement and evaluation courses during the teachers' training period (Bunker \& Thorpe, 1986). It is so much easier to evaluate separate techniques than other aspects of games, such as decision- 
making, which may pull physical educators toward the technical side of games "at worst this structure has led to an introductory session unrelated to what is to follow, a technique session seen as essential only by the teacher, and a game inappropriate to the ability of many of the children" (Turner \& Martinek, 1995, p. 53).

Problems arise when instructors believe that a skilled player already possesses the necessary prerequisites for performing a task in any game-like situation or when learning is de-contextualized. Students practice a skill wanting to know where and when the skill will apply based on specific environmental cues; without this frame of reference practice becomes meaningless. The isolated techniques have little relevance and students lose their motivation (Turner \& Martinek, 1995).

Often, techniques for sport are developed by the use of drills practiced in isolation and many times the progression never reaches game play, which results in students showing some form of the mature motor patterns with all of them trying to perform exactly as the teacher described. Therefore, students game playing capabilities are based on copying scripted movement patterns versus developing full understanding of the game situation. This produced many students who could execute the techniques under ideal conditions. However, if an unexpected situation arose, they were not prepared for the unexpected or able to alter the technique. Teachers acted as a "delivery system - a one way transfer of information and skills" to their students (Shor, 1986, p. 415).

There seems to be a missing link between learning the techniques to play a sport and applying them in the actual game. Many children are expected to move off-theball and utilize space successfully without being allowed to explore these concepts. 
They are put into a full game situation with many teammates only to have few opportunities to be directly involved during the game, are continually pressured by opponents and time constraints, and are expected to "move" or "do something" without understanding basic offensive or defensive tactics.

Teachers must employ instructional models to better prepare students in becoming proficient movers in game situations. Young children (elementary and middle school) and novice players need activities that allow them to explore off-the-ball movement options and apply sport specific techniques in a game form that will establish a foundation for future sport tactics. They need the chance to discover movement options through exploration to help them solve tactical problems, which occur during game play. If they have experiences in and knowledge of game tactics in a general sense (those that apply to all invasion/territorial games), they will not be overburdened with having to learn both, techniques and tactics for each sport/game presented later on. Simple keep-away or modified games that emphasize possession and dispossession may be the way to bridge the learning of techniques and the ability to determine their use in a contest.

In order to be effective, players must develop their knowledge of and performance in, off-the-ball movements as well as on-the-ball skills. Invasion/Territorial games are played in a dynamic environment that changes constantly and relies on interdependence between participants. Because of these factors, it is imperative that instruction matches the demands of the activity by giving students opportunities to function in fast paced situations. Physical educators should be concerned with determining how they can best help students play games. Practitioners need to "gain a 
better understanding of what children are likely to learn in different instructional contexts" (Rink, French, \& Tjeerdsma, 1996, p. 417). The best option for invasion/territorial games may be a situated learning perspective where the teacher/coach modifies games to help students/players explore the interdependence of the player, environment, and task in specific tactical situations. The situated learning theory has an "emphasis on decision making based on perception and the adaptation of new knowledge to existing knowledge (Light \& Fawns, 2003, p. 164).

\section{Future Research}

Results of this tactical performance and tactical knowledge study indicate the need for future research in solidifying the validity for and establishment of inter-observer reliability when using the GPAI (initial validation has been established) and TKI as formative instruments to assess game performance and tactical knowledge. Interobserver reliability was easily attained for the TKI in the preliminary validation study and actual study conducted by the researcher. However inter-observer reliability was harder to attain for some of the GPAI components. The number of criteria the coders were looking for may have been too extensive to score at one time and did require additional viewing sessions. Also, more consistent interpretation between coders, through the development of very clear criteria, must be established for the GPAI to be an effective tool.

Additional research testing other GPAI on-the-ball skills and off-the-ball movement components for both offense as well as defense need to be conducted as there have been only a few empirical studies completed to test game performance. A replication study having an off-the-ball defensive tactical problem as the theme could 
be conducted then compared to the results of this offensive off-the-ball study to determine if the more familiar offensive scenario provided higher scores than the defensive scenario. Additional research also must be conducted to clarify the relationship between tactical knowledge and tactical performance and determine if the GPAI and TKI are appropriate instruments to measure the relationship.

This study could be replicated to analyze the tactical performance of established interscholastic, intercollegiate, club, and professional teams. The interdependence of teammate and opponent movements and decisions may impact the outcomes more clearly than the random selection of teams that were established for this study (especially for the synchronized movement decisions). Teammates, who have played together over time, start to anticipate each others' moves. This familiarity among players often produce well timed cuts and better support because of quicker and more accurate decision-making capabilities. Teammates know each others' tendencies based on perceived strengths, and weaknesses, which aids in selecting the appropriate course of action.

The use of the GPAI and TKI to test tactical performance and tactical knowledge can be utilized to study the effects of using the Teaching Games for Understanding or Tactical Approach instructional models (indirect teaching style) versus direct or teacher-centered instructional models. Treatment and control groups can be pre- and post tested to see if players' performance is enhanced when using the different methods. This study focused on collegiate level participants, so additional research can focus on elementary, middle school and high school age children. 
Since tactical knowledge traditionally has not been the focus in physical education classes or team sport practice, future research must be conducted to determine if earlier tactical emphasis, both at the curriculum level (instruction in tactics during elementary school versus later on) and the sport unit level (equal tactical emphasis with skill development) affects the development of more effective games players. Research must be conducted to test if or how well tactical knowledge is transferred between similar game types (e.g., similar tactics for field hockey and lacrosse). Research needs to be completed to determine if the use of small games (e.g., three versus three, four versus four) or simple keep-away games enhance players' tactical knowledge and increase the probability of transfer to full team sport form.

This study found an overall lack of variety and quality in the participants' tactical knowledge responses concerning how to solve the tactical problem. Research focusing on off-the-ball tactical options need to be conducted. To develop better tactical knowledge, which is a major component of effective game play; teachers and coaches need to know what current tactics their students/players access then what methods help them add to their tactical repertoire. From the findings of this study, it appears that all students/players, regardless of expertise level, would benefit from experiences that center on off-the-ball tactical awareness.

\section{Conclusion}

Turner and Martinek (1992) ask that teachers question themselves as to why they teach games. "Is it to learn a flick in hockey, a punt in rugby, or a side foot pass in soccer" (p. 17); or is it to function competently within the contest itself? If it is the latter, then teaching only techniques will not be sufficient; the instructional model 
should be one that also addresses response selection, which is based on previous experience, facts, and current conditions. Concentrating on response selection is even more important with high-strategy, continuous, open sports; those with offense and defense interaction and has task demands that are constantly changing (Thomas, 1994).

The inability to fully support the hypotheses of this study may be an indication of what happens when students and players are not exposed to all aspects of game play. It is necessary to provide experiences that not only work on improving skills, but also develops the off-the-ball movement to complement or apply those skills. It is essential to enhance tactical awareness since players spend most of the time in an off-the-ball position. However, tactics that address where and when to move while in off-the-ball positions are never explicitly taught. The participants of this study reported that drills to practice skills were emphasized in physical education and team sport practice.

Expertise level should be indicative of players' skill level and tactical awareness; however, results of this study do not reflect this assumption. Perhaps the skill level of the Experts might have been better, but they did not display more intricate or creative movement to be more effective off-the-ball movers during game play. A lack of offthe-ball emphasis may have been the cause for similarities in the movement for Novice, Intermediate, and Expert players.

Also there was not a distinctive separation in off-the-ball tactical knowledge for the different levels of expertise (other than between Novice and Expert groups) and tactical knowledge did not parallel tactical performance. This implies that players were moving, but may not have made the appropriate move or did not consciously 
make decisions based on environmental cues. This calls into question whether or not players were thinking tactically during game play and were they ever taught to think tactically? There also was a lack of variety and creativity in solutions the Experts provided and while the responses were significantly different from Novices, as a group, their responses were not superior to those of the Intermediate group. This implies that tactical knowledge was not exceptionally well developed even for the Expert group. Since so much game time is spent off-the-ball, tactical awareness may be the ultimate factor in creating more effective players. 


\section{Appendix A - Glossary of Terms}

Directional Keep-Away Game: A scoring opportunity occurs when the offensive team passes the ball in the air and when the situation presents itself the ball is passed over the end-line of the boundary to a teammate who catches it in the air.

Game Performance Assessment Instrument: Authentic assessment instrument used to determine a player's performance in a game setting.

Off-the-ball movement: Movement in a game when not in possession of the ball.

On-the-ball movement: Movement in the game when in possession of the ball (e.g. dribbling or passing).

Rapport of Strength: Territorial game players' response selection and movement execution choices are dependent on what their teammates and opponents are doing within the game.

Skill: An on-the-ball sport movement executed within the context of the game (e.g. passing in a $3 \vee 3$ aerial basketball game). A skill is the application of a technique.

Tactical Awareness: The ability to identify problems that arise while a game is in progress and to select the skills necessary to solve these problems (Mitchell, Griffin, \& Oslin, 1994, p. 21).

Tactical Knowledge Instrument: Scoring rubric used to assess a player's knowledge of tactical problems associated with team sports.

Technique: An on-the-ball sport movement executed in isolation (e.g. dribbling a basketball around cones).

Territorial or Invasion Game: Type of game where a team moves the ball into the opponents' territory to score by shooting into a goal or passing over an end-line (e.g. soccer, football, basketball). 
Appendix B - Tactical Knowledge Instrument (TKI)

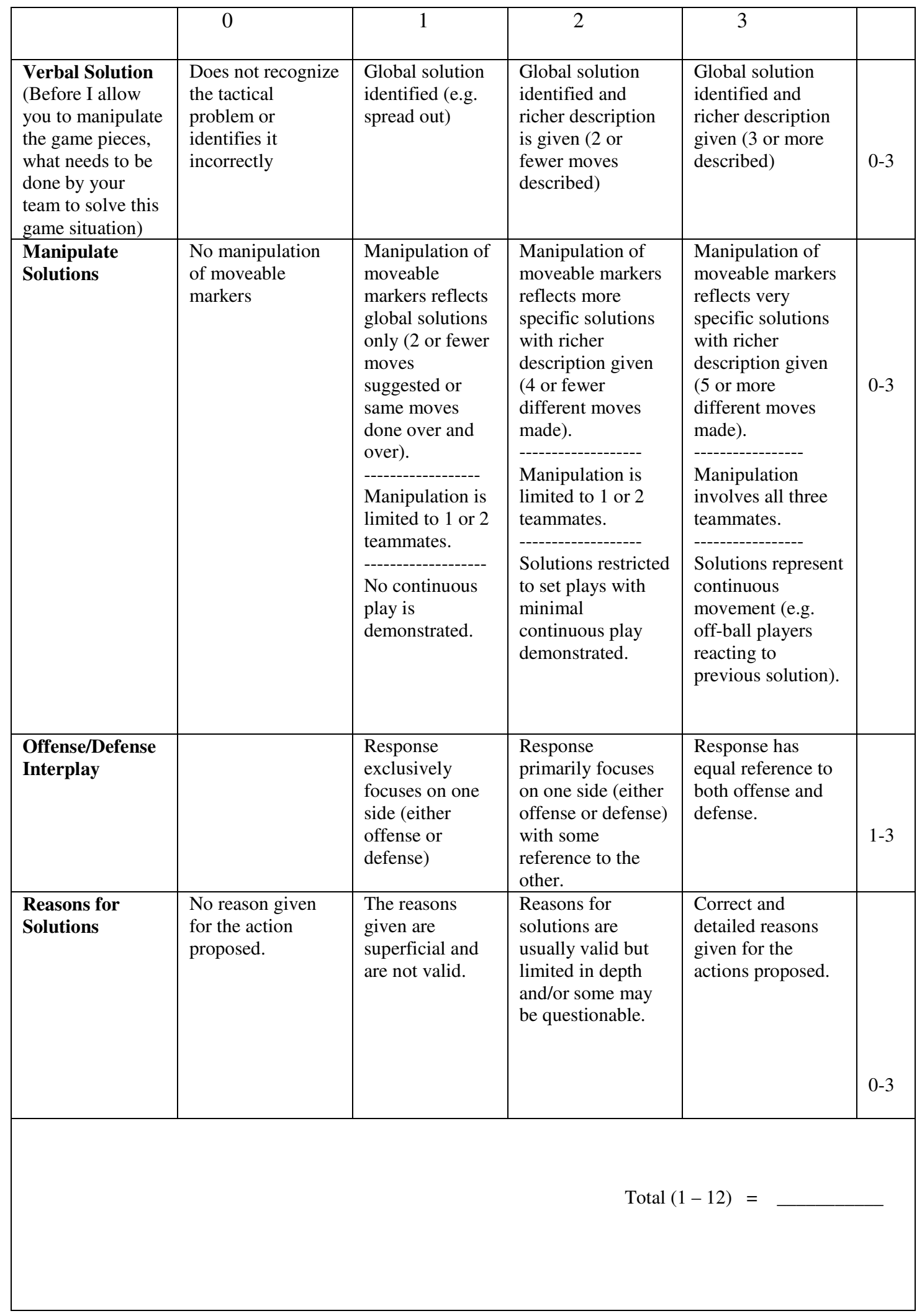


Appendix C - Game Performance Assessment Instrument (GPAI)

\section{Identification Number}

\section{Scoring Key:}

5 = Almost Always - very few missed opportunities $(<10 \%)$

$4=$ Usually - consistently takes advantage of the opportunities $(61 \%-90 \%)$

$3=$ Inconsistently - takes advantage of, but also often misses the opportunity (40\% $60 \%)$

$2=$ Usually Fails - misses opportunity more times than not $(39 \%-10 \%)$

1 = Almost Always Fails - hardly ever takes advantage of the opportunity $(<10 \%)$

\section{Components and Criteria}

Decision Making: a. Determines they are not in an open passing lane and moves into an open space. b. Cuts into space vacated by a teammate or moves to another space so a teammate can cut into their space (synchronized movement with teammates).

Support: a. Comes back or lateral to support the player with the ball when they are in trouble to receive a short possession pass (avoids a 10 second count).

b. Moves to open space toward the target area at the appropriate angle.

Adjust: a. After the player passes, he/she moves into a new space.

b. Tries to elude (dodge or fake) the opponent prior to cutting into space.

c. Moves to meet the pass.

\begin{tabular}{|l|l|l|}
\hline \multicolumn{2}{|c|}{ Decision Making } & \multicolumn{1}{|c|}{ Support Adjust } \\
a. & a. & a. \\
b. & b. & b. \\
& & c. \\
\hline
\end{tabular}


Appendix D - Participant Questionnaire

Participant's Name

Telephone Number

T Shirt Size

The purpose of this questionnaire is to give the researcher background information about the participant's experiences in territory games (going into the opponent's territory to score). This information will be used to draw a random sample for the study. Please complete Section A - E as thoroughly as possible.

A. Circle the sports (territorial games) you have played. On the line next to the game, write down how often you play(ed) the games you participate(d) in (i.e. once a week, daily, during the season, during class, every once in a while etc.).

\section{Basketball}

Field Hockey

Ice Hockey

Street/Floor Hockey

Flag/Touch Football

Football

Lacrosse

Rugby

Soccer

Speedball

Ultimate Frisbee

(other invasion game)

(other invasion game)

(noninvasion game e.g. baseball, volleyball) 
B. Indicate where you participated in each territory game by writing the name of the. game beside each appropriate source

Backyard with family and/or friends

Youth League or Club

Physical Education Class

Intramurals (school or college)

Interscholastic

Intercollegiate

C. In the space provided, write down any awards (Most Valuable Player, Most Improved, All-Division, All-State etc.) you received for playing either interscholastic or intercollegiate sports. Be sure to indicate the sport along with the award. 
D. For any interscholastic or intercollegiate territorial sports played, indicate: 1 . how many years you played and 2 . whether you were a starter, regular substitute (first or second off the bench), reserve $\left(3^{\text {rd }}, 4^{\text {th }}, 5^{\text {th }}\right.$ off the bench) or occasionally used reserve.

Sport

Years Starter, Regular Sub,

Played Reserve, Occasional Reserve

E.

1. Which statement describes a typical physical education lesson you participated in while in elementary school? (Choose one)
a. drills to work on skills then game play to emphasize the skills
b. game followed by a drill (if the game play was flawed) then a game with the emphasis on tactics (moves used to get by an opponent)
c. recreational game play with little to no instruction
d. cannot remember

2. Which statement describes a typical physical education lesson you participated in while in middle and high school? (Choose one)
a. drills to work on skills then game play to emphasize the skills
b. game followed by a drill if the game play was flawed then a game with the emphasis on tactics (moves used to get by an opponent)
c. recreational game play with little to no instruction
d. cannot remember

3. Which statement describes a typical practice session you participated in while playing a sport? (Choose one)
a. drills to work on skills then game play to emphasize the skills
b. game followed by a drill if the game play was flawed then a game with the emphasis on tactics (moves used to get by an opponent)
c. recreational game play with little to no instruction
d. did not participate in sports 
4. Circle the closest percentage of time in physical education class that was spent on:

drills $\quad<25 \% \quad 50 \% \quad 75 \% \quad>75 \%$

game related activities $\quad<25 \% \quad 50 \% \quad 75 \% \quad>75 \%$

(e.g. lead up games)

full or official game $\quad<25 \% \quad 50 \% \quad 75 \% \quad>75 \%$

5. Circle the closest percentage of time in extracurricular sport practice that was spent on:

drills $\quad<25 \% \quad 50 \% \quad 75 \% \quad>75 \%$

game related activities $\quad<25 \% \quad 50 \% \quad 75 \% \quad>75 \%$

(e.g. lead up games)

full or official game $\quad<25 \% \quad 50 \% \quad 75 \% \quad>75 \%$

6. Were you ever specifically introduced to the Tactical Approach to team sports or the Games for Understanding instructional model in physical education class or extracurricular sports? (Circle one)

YES NO 
Appendix E - Consent to Participate in Research

I understand that I have been asked to participate in this study to field test assessment instruments for game performance.

I acknowledge that I will be asked to complete a questionnaire that documents my level of experience in team sports, participate in an interview where I will be asked to solve a tactical scenario, and play an eight minute keep-away game in the gymnasium. The interview and game play will be videotaped. The study will take approximately two hours during a one-day span of time.

I understand this study may include risk of physical injury while playing the keepaway game in the gymnasium.

I understand that my responses will be kept confidential to the extent permitted by law and that I may request an interpretation of my results once the study is completed. Only those involved with the study will view the videotapes. The videotapes will be secured in a locked closet in the Health and Physical Education Department office at Rhode Island College upon completion of the study.

I understand that my participation in this study is entirely voluntary and that I may discontinue my participation at any point without penalty to myself. I understand that my instructor will not know whether I chose to participate in the study or not. I acknowledge that the contents of this form have been explained to me and that I have been given an opportunity to ask questions. Permission to use this form will expire on September 30, 2006. I have been given a copy of this form.

I understand that if I have any questions about the study or if I experience any discomfort or have any concerns that I would like to express I may contact: Dr. Karen Castagno at 456-8866; Dr. Bennett Lombardo at 456-9688; or Professor Robin Kirkwood Auld at 456-8880.

I DO CONSENT TO PARTICIPATE IN THIS RESEARCH PROJECT 


\section{Bibliography}

Bunker, D., \& Thorpe, R. (1983). A model for the teaching of games in secondary schools. Bulletin of Physical Education, 19, 5-8.

Bunker, D., \& Thorpe, R. (1986). Is there a need to reflect on our games teaching? In R. Thorpe, D. Bunker, \& L. Almond. (Eds.), Rethinking games teaching.(pp. 25-34). Loughborough, England: Department of Physical Education and Sports Science University of Technology.

Blomqvist, M., Luhtanen, P., Laakso, L., \& Keskinen, E. (2000). Validation of a video-based game-understanding test procedure in badminton. Journal of Teaching in Physical Education, 19, 325-337.

Butler, J., Griffin, L., Lombardo, B., \& Nastasi, R. (Eds.). (2003). Teaching games for understanding in physical education and sport. Reston, VA: National Association for Sport and Physical Education.

French, K., \& McPherson, S. (2004). The development of expertise. In M.R. Weiss (Ed.), Developmental sport and exercise psychology: A lifespan perspective (pp. 403-423). Morgantown, WV: Fitness Information Technology.

French, K., Spurgeon, J., \& Nevett, M. (1995). Expert-novice differences in cognitive and skill execution components of youth baseball performance. Research Quarterly for Exercise and Sport, 66, 194-201. 
French, K., Werner, P., Rink, J., Taylor, K., \& Hussey, K. (1996). The effects of a 3week unit of tactical, skill or combined tactical and skill instruction on badminton performance of ninth-grade students. Journal of Teaching in Physical Education, 15, 418-438.

French, K., Werner, P., Taylor, K., Hussey, K., \& Jones, J. (1996). The effects of a 6week unit of tactical, skill, or combined tactical and skill instruction on badminton performance of ninth-grade students. Journal of Teaching in Physical Education, 15, 439-463.

French, K., \& Thomas., J. (1987). The relation of knowledge development to children's basketball performance. Journal of Sport Psychology, 9, 15-32.

Graham, K., Ellis, S., Williams, C., Kwak, E., \& Werner, P. (1996). High- and Lowskilled students' academic achievement and instructional performance in a 6week badminton unit. Journal of Teaching in Physical Education, 15, 477-489.

Grehaigne, J., \& Godbout, P. (1995). Tactical knowledge in team sports from a constructivist perspective. Quest, 47, 490-505.

Grehaigne, J. F., Godbout, P., \& Bouthier, D. (1997). Performance assessment in team sports. Journal of Teaching in Physical Education, 16, 500-516.

Grehaigne, J. F., Godbout, P., \& Bouthier, D. (2001). The teaching and learning of decision making in team sports. Quest, 53, 59-76.

Griffin, L., \& Butler, J. (Eds.). (2005). Teaching games for understanding: Theory, research, and practice. Champaign, IL: Human Kinetics. 
Griffin, L., Dodds, P., Placek, J., \& Tremino, F. (2001). Middle school students' conceptions of soccer: Their solutions to tactical problems [Monograph]. Journal of Teaching in Physical Education, 20, 324-340.

Griffin, L., Mitchell, S., \& Oslin, J. (1997). Teaching sport concepts and skills: A tactical games approach. Champaign, IL: Human Kinetics.

Howarth, K., \& Walkuski, J. (2003). Teaching tactical concepts with preservice teachers. In J. Butler, L.Griffin, B. Lombardo, R. Nastasi. (Eds.), Teaching games for understanding in physical education and sport (pp. 127-137). Reston, VA: National Association for Sport and Physical Education.

Kirk, D. (1983). Theoretical guidelines for teaching for understanding. Bulletin of Physical Education, 19, 41-45.

Light, R.(2005). Making sense of the chaos. In L.Griffin, \& J. Butler. (Eds.), Teaching games for understanding: Theory, research, and practice. (pp. 169-181). Champaign, IL: Human Kinetics.

Light, R., \& Fawns, R. (2003). Knowing the game: Integrating speech and action in games teaching through TGfU. Quest, 55, 161-176.

McPherson, S. (1994). The development of sport expertise: Mapping the tactical domain. Quest, 46, 223-240.

McPherson, S., \& French, K. (1991). Changes in cognitive strategies and motor skill in tennis. Journal of Sport and Exercise Psychology, 13, 26-41.

McPherson, S., \& Thomas, J. (1989). Relation of knowledge and performance in boys' tennis: Age and expertise. Journal of Experimental Child Psychology, 
$48,190-211$.

Mitchell, S., Griffin, L., \& Oslin, J. (1994). Tactical awareness as a developmentally appropriate focus for the teaching of games in elementary and secondary physical education. Physical Educator, 51(1), 21-28.

Mitchell, S., Oslin, J., \& Griffin, L. (1995). The effects of two instructional approaches on game performance. Pedagogy in Practice, 1(1), 36-48.

Mitchell, S., Oslin, J., \& Griffin, L. (2003). Sport foundations for elementary physical education. Champaign, IL: Human Kinetics.

Nevett, M., Rovegno, I., \& Babiarz, M. (2001). Fourth-grade children's knowledge of cutting, passing and tactics in invasion games after a 12-lesson unit of instruction [Monograph]. Journal of Teaching in Physical Education, 20, 389401.

Nevett, M., Rovegno, I., Babiarz, M. \& McCaughtry, N. (2001). Changes in basic tactics and motor skills in an invasion-type game after a 12-lesson unit of instruction [Monograph]. Journal of Teaching in Physical Education, 20, 352-369.

Oslin, J., Mitchell, S., \& Griffin, L. (1998). The game performance assessment instrument (GPAI): Development and preliminary validation. Journal of Teaching in Physical Education, 17, 231-243.

Piltz, W. (2003). Teaching and coaching using a 'play practice' approach. In J. Butler, L.Griffin, B.Lombardo, R. Nastasi. (Eds.), Teaching games for understanding in physical education and sport (pp. 189-200). Reston, VA.: National Association for Sport and Physical Education. 
Placek, J., Griffin, L., \& Dodds, P. (2001). Fifth/Sixth grade students' views of "bunching up": A study of alternative conceptions in soccer. Journal of Sport Pedagogy, 7(2), 24-42.

Richard, J., Godbout, P., Tousignant, M., \& Grehaigne, J. (1999). The try-out of a team sport performance assessment procedure in elementary physical education classes. Journal of Teaching in Physical Education, 18, 336-356.

Rink, J., French, K., \& Graham, K. (1996). Implications for practice and research. Journal of Teaching in Physical Education, 15, 490-502.

Rink, J., French, K., \& Tjeerdsma, B. (1996). Foundations for the learning and instruction of sport and games. Journal of Teaching in Physical Education, 15, 399-417.

Shor, I. (1986). Equity is excellence: Transforming teacher education and the learning process. Harvard Educational Review, 56, 406-426.

Thomas, K. (1994). The development of sport expertise: From Leeds to MVP legend. Quest, 46, 199-210.

Thorpe, R., Bunker, D., \& Almond, L. (Eds.). (1986). Rethinking games teaching. Loughborough, England: Department of Physical Education and Sports Science University of Technology.

Turner, A., \& Martinek, T. (1992). A comparative analysis of two models for teaching games: Technique approach and game-centered (tactical focus) approach. International Journal of Physical Education, 29, 15-31.

Turner, A., \& Martinek, T. (1995). Teaching for understanding: A model for 
improving decision making during game play. Quest, 47, 44-63.

Veal, M. (1992). The role of assessment in secondary physical education - A pedagogical view. Journal of Physical Education, Recreation and Dance, 63, $88-92$.

Weiss, M.R. (Ed.). (2004). Developmental sport and exercise psychology: A lifespan perspective. Morgantown, WV: Fitness Information Technology. 